\title{
Evaluation of Technetium Getters to Improve the Performance of Cast Stone
}

\author{
JJ Neeway \\ NP Qafoku \\ RJ Serne \\ AR Lawter \\ JR Stephenson \\ WW Lukens \\ JH Westsik, Jr.
}

November 2015

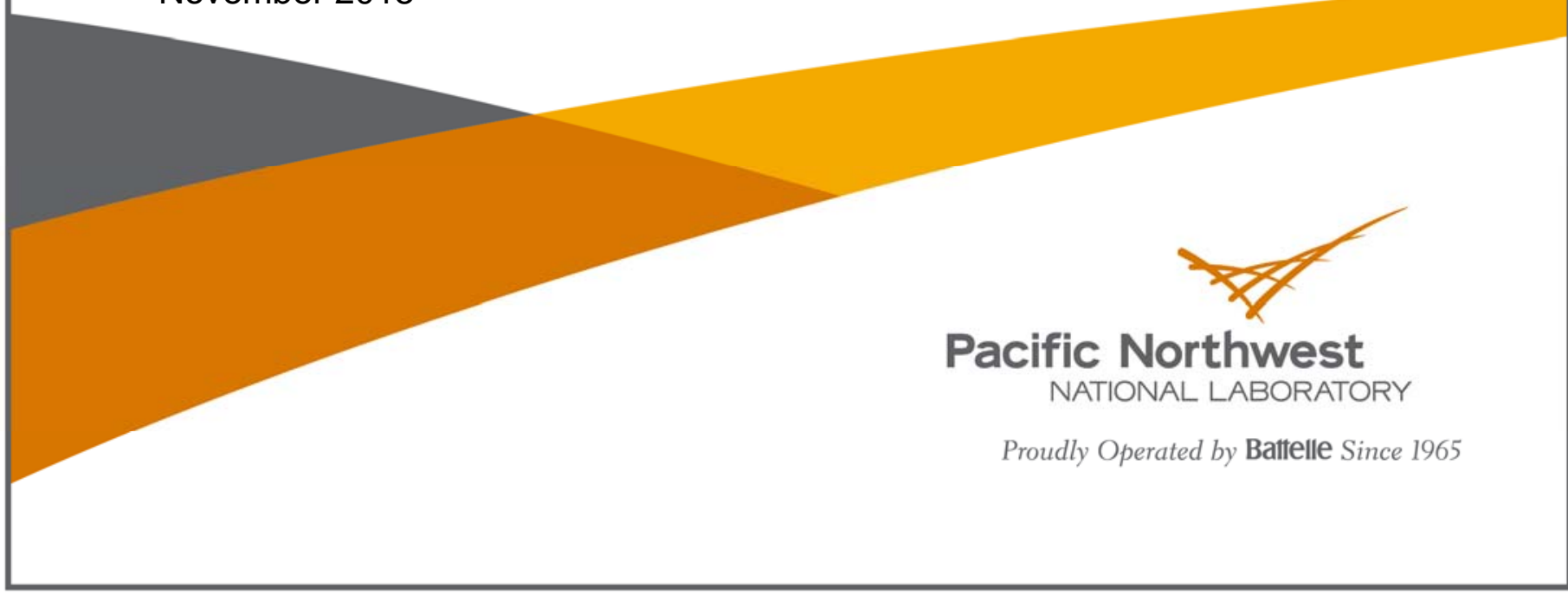




\title{
DISCLAIMER
}

This report was prepared as an account of work sponsored by an agency of the United States Government. Neither the United States Government nor any agency thereof, nor Battelle Memorial Institute, nor any of their employees, makes any warranty, express or implied, or assumes any legal liability or responsibility for the accuracy, completeness, or usefulness of any information, apparatus, product, or process disclosed, or represents that its use would not infringe privately owned rights. Reference herein to any specific commercial product, process, or service by trade name, trademark, manufacturer, or otherwise does not necessarily constitute or imply its endorsement, recommendation, or favoring by the United States Government or any agency thereof, or Battelle Memorial Institute. The views and opinions of authors expressed herein do not necessarily state or reflect those of the United States Government or any agency thereof.

\author{
PACIFIC NORTHWEST NATIONAL LABORATORY \\ operated by \\ BATTELLE \\ for the \\ UNITED STATES DEPARTMENT OF ENERGY \\ under Contract DE-AC05-76RL01830
}

Printed in the United States of America
Available to DOE and DOE contractors from the Office of Scientific and Technical Information, P.O. Box 62, Oak Ridge, TN 37831-0062; ph: (865) 576-8401 fax: $(865) 576-5728$
email: reports@adonis.osti.gov
Available to the public from the National Technical Information Service 5301 Shawnee Rd., Alexandria, VA 22312 ph: (800) 553-NTIS (6847) email: orders $a$ ntis.gov $<$ http://www.ntis.gov/about/form.aspx> Online ordering: http://www.ntis.gov




\title{
Evaluation of Technetium Getters to Improve the Performance of Cast Stone
}

\author{
JJ Neeway \\ NP Qafoku \\ RJ Serne \\ AR Lawter \\ JR Stephenson \\ WW Lukens \\ JH Westsik, Jr.
}

November 2015

Prepared for

the U.S. Department of Energy

under Contract DE-AC05-76RL01830

Pacific Northwest National Laboratory

Richland, Washington 99352 


\section{Revision History}

\begin{tabular}{|c|c|l|l|}
\hline $\begin{array}{c}\text { Revision } \\
\text { Number }\end{array}$ & $\begin{array}{c}\text { Interim } \\
\text { Change } \\
\text { No. }\end{array}$ & $\begin{array}{c}\text { Effective } \\
\text { Date }\end{array}$ & \multicolumn{1}{c|}{ Description of Change } \\
\hline 0 & 0 & $9 / 2014$ & Initial issue. \\
\hline 1 & 0 & $11 / 2015$ & $\begin{array}{l}\text { Revision includes an additional acknowledgement to a } \\
\text { provider of one of the getter materials and minor editorial } \\
\text { changes. }\end{array}$ \\
\hline & & & \\
\hline & & & \\
\hline & & & \\
\hline & & & \\
\hline & & & \\
\hline
\end{tabular}




\section{Executive Summary}

Cast Stone has been selected as the preferred waste form for solidification of aqueous secondary liquid effluents from the Hanford Tank Waste Treatment and Immobilization Plant (WTP) process condensates and low-activity waste (LAW) melter off-gas caustic scrubber effluents. Cast Stone is also being evaluated as a supplemental immobilization technology to provide the necessary LAW treatment capacity to complete the Hanford tank waste cleanup mission in a timely and cost-effective manner. One of the major radionuclides that Cast Stone has the potential to immobilize is technetium (Tc). Recent relatively short-term (63 day) leach tests conducted on both LAW and secondary waste Cast Stone monoliths indicated that ${ }^{99} \mathrm{Tc}$ diffusivities were at or near diffusivities where the groundwater at the 100-m down-gradient well would exceed the allowable maximum permissible ${ }^{99} \mathrm{Tc}$ concentrations. There is, therefore, a need and an opportunity to improve the retention of Tc in the Cast Stone waste form. One method to improve the performance of the Cast Stone waste form is through the addition of "getters" that selectively sequester Tc inside Cast Stone.

In order to determine the effectiveness of getters prior to their solidification in Cast Stone, a series of batch sorption experiments has recently been performed at Pacific Northwest National Laboratory (PNNL) (Qafoku et al. 2014). In that series of tests, seven getter materials were tested for Tc: blast furnace slag 1 (BFS 1) (northwest source), BFS 2 (southeast source), $\mathrm{Sn}$ (II)-treated Apatite, Sn(II) chloride, nanoporous tin phosphate, KMS-2 (a potassium-metal-sulfide) (Mertz et al. 2013), and Tin hydroxyapatite. These getters had previously been identified as candidates for the removal of Tc(VII) from waste solutions (Pierce et al. 2010b). The tests involved placing the solid getter material in contact with ${ }^{99} \mathrm{Tc}$-spiked waste solutions for periods up to 45 days with periodic solution sampling to monitor the evolution of ${ }^{99} \mathrm{Tc}$ in solution. Two different solution media, deionized (DI) water and a 7.8 M Na Ave LAW waste simulant, were used. All of the getters demonstrated reasonable effectiveness in removing Tc from DI water whereas results from experiments using the $7.8 \mathrm{M} \mathrm{Na}$ Ave LAW (pH 13.5) simulant showed no, to a very small, capacity to remove Tc.

The present report serves as a continuation of the experiments performed by Qafoku et al. (2014). More specifically, the set of experiments presented in this report attempts to investigate further the reasons behind satisfactory Tc removal from DI water compared with poor Tc removal from the $7.8 \mathrm{M} \mathrm{Na}$ Ave LAW simulant. If these reasons can be identified, systems that optimize Tc removal from the $7.8 \mathrm{M}$ $\mathrm{Na}$ Ave LAW simulant can be designed and incorporated into the Cast Stone production process. As a first step in understanding the differences in Tc removal from the two systems, we examined the post-reaction solids from DI water and 7.8 M Na Ave simulant experiments obtained from Qafoku et al. (2014) using scanning electron microscopy/energy dispersive spectroscopy (SEM/EDS) and bulk x-ray absorption fine structure analysis (XAFS) spectroscopy. As a second step in understanding the poor removal of Tc from the $7.8 \mathrm{M} \mathrm{Na}$ Ave LAW simulant, new batch sorption tests were performed using the getters BFS 1, BFS 2, and Tin Apatite. These three getters were chosen because the BFS is a dry ingredient in Cast Stone formulation and Tin Apatite was available in large quantities and showed promising results from the previous set of experiments in terms of Tc removal. The batch sorption experiments were performed to examine if the limited removal of Tc was due to an insufficient getter mass in the system and to examine the competitive effects of $\mathrm{Cr}$ on $\mathrm{Tc}$ removal. $\mathrm{Cr}$, which is present in the LAW simulant and can be reduced from $\mathrm{Cr}(\mathrm{VI})$ to $\mathrm{Cr}(\mathrm{III})$, may be responsible for mitigating the effectiveness of Tc reduction and removal from the LAW simulant. 
For the set of solid-state characterization techniques, the aim was to identify the location and oxidation state of Tc on the surface of the getters. Results indicate that the Tc location and oxidation state are dependent on the type of getter material that is used. For example, the BFS samples demonstrated an inhomogeneous distribution of $\mathrm{Tc}$ on the getter and the $\mathrm{Tc}$ was present as $\mathrm{TcO}_{4}^{-}$, i.e. in the oxidized form. For the Tin Apatite sample, the Tc was distributed evenly across the getter surface and the Tc was present in the reduced $\mathrm{TcO}_{2}$ form. These results, along with results from other getters, have given insight into the various mechanisms responsible for Tc removal from solution. If the exact chemistry and structure of Tc sites can be identified, systems can be designed that promote their formation and this may eventually lead to higher Tc retention in the Cast Stone waste form. This process must also be effective in representative LAW simulants.

Results from the new sets of batch sorption experiments, where a greater mass of getter was introduced into the system, show that in DI water a more complete and faster removal of Tc is achieved for all three getters. However, similar experiments performed in the $7.8 \mathrm{M} \mathrm{Na}$ Ave simulant do not show a significant increase in Tc removal when a greater getter mass is used. For experiments examining the competitive effects of $\mathrm{Cr}$ and $\mathrm{Tc}$, results show that $\mathrm{Cr}$ competes directly with $\mathrm{Tc}$ for removal from solution by getters. Because the Cr concentration in the $7.8 \mathrm{M} \mathrm{Na}$ Ave simulant is roughly $1800 \mathrm{ppm}$ compared to $5 \mathrm{ppm}$ for Tc, this competitive reaction is very important. Therefore, the reason for not seeing an increase in Tc removal from the experiments where a greater getter mass is used may still be due to an insufficient amount of getter to effectively remove all of the $\mathrm{Cr}$ and $\mathrm{Tc}$ into solution. Further studies should aim to mitigate the effect of $\mathrm{Cr}$ for effective removal of Tc by getter materials that may be used in Cast Stone formulations. 


\section{Acknowledgments}

This work was completed as part of the Technetium Management-Hanford Site project. Support for this project came from the U.S. Department of Energy's Office of Environmental Management.

The KMS-2 material described in this study was provided by the group of Prof. Mercouri G. Kanatzidis at Northwestern University. The authors wish to thank Dr. Wooyong Um for his technical peer review, Bill Dey for editorial review and quality assurance, and Steven Baum and Ian Leavy of the Geosciences Group for help in running the ICP-MS analyses. 



\section{Acronyms}

BFS

DI

DOE

DOE-ORP

EDS

EPA

EQL

EXAFS

HTWOS

ICP-MS

IDF

ILAW

LAW

$\mathrm{Na}$

PNNL

PTFE

SEM

Tc

TC\&WM EIS

WTP

XAFS

XANES blast furnace slag

deionized

U.S. Department of Energy

U.S. Department of Energy Office of River Protection

energy dispersive spectroscopy

U.S. Environmental Protection Agency

estimated quantitation limit

extended x-ray absorption fine structure

Hanford Tank Waste Operations Simulator

inductively coupled plasma mass spectroscopy

Integrated Disposal Facility

immobilized low-activity waste

(Hanford) low-activity waste

sodium

Pacific Northwest National Laboratory

polytetrafluoroethylene

scanning electron microscopy

technetium

Tank Closure and Waste Management Environmental Impact Statement

Hanford Tank Waste Treatment and Immobilization Plant

$\mathrm{x}$-ray absorption fine structure

x-ray absorption near-edge structure 



\section{Contents}

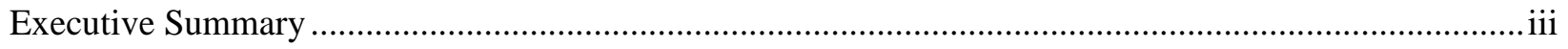

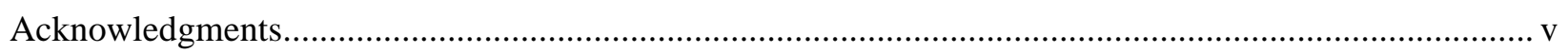

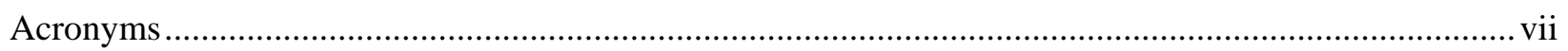

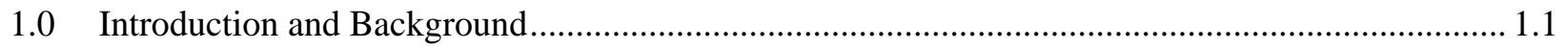

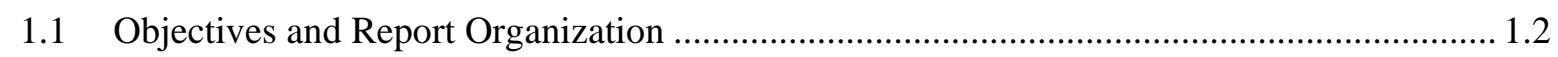

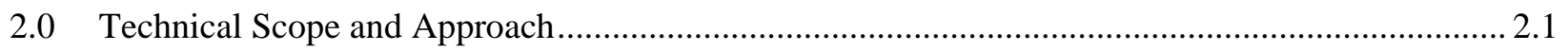

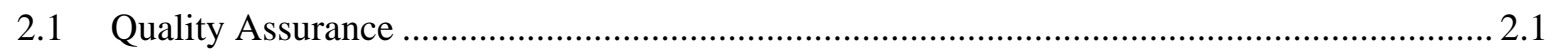

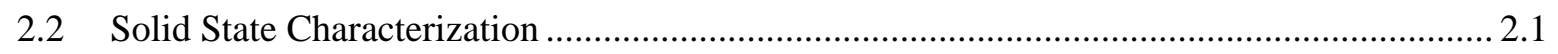

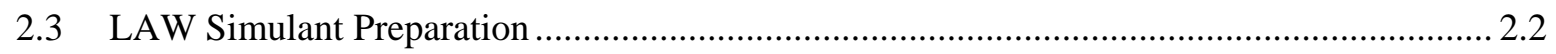

2.4 Batch Sorption Tests Method ......................................................................................... 2.2

2.4.1 The Effect of the Solid (mass) to Solution (volume) Ratio ....................................... 2.3

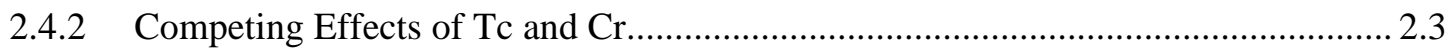

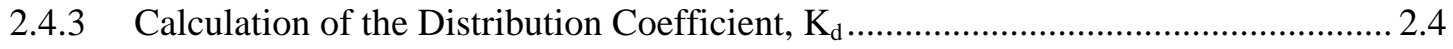

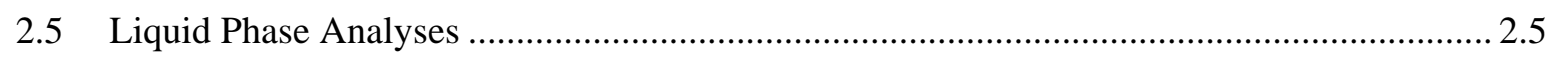

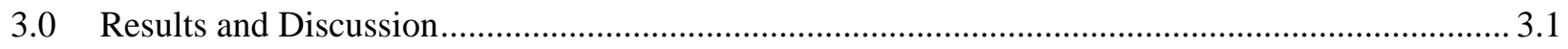

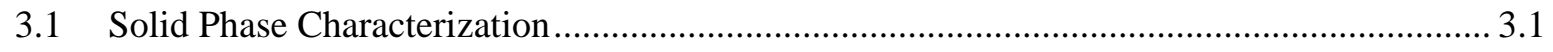

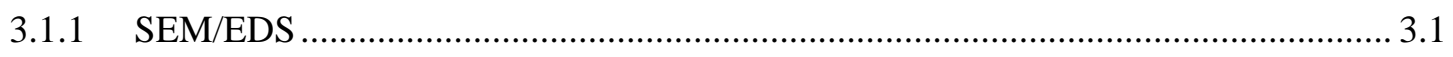

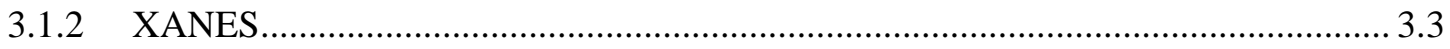

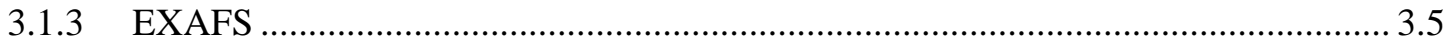

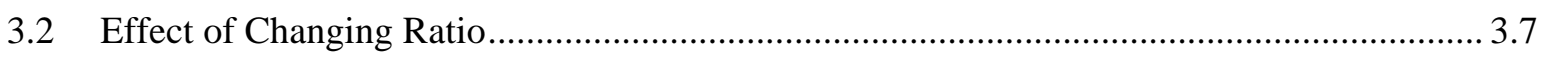

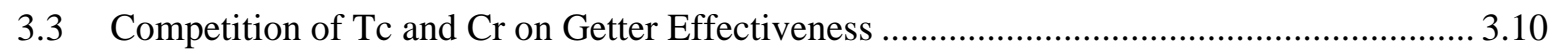

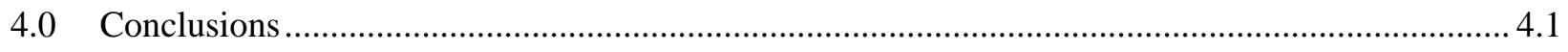

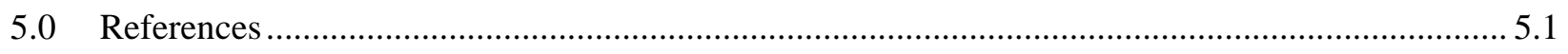

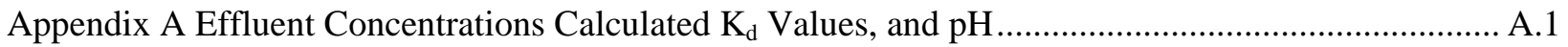




\section{Figures}

3.1. SEM/EDS Results for a Tin Apatite Sample Used in a DI Water Experiment for Tc

Removal

3.2. SEM/EDS Results for a BFS 2 Sample Used in a DI Water Experiment for Tc Removal..............3.3

3.3. XANES Spectrum and Fit for Sample a) Sn-apatite, b) BFS 2, c) KMS-2, d) Tin Hydroxyapatite.

3.4. EXAFS Spectrum and Fit and Its Fourier Transform Obtained from a Tin Apatite Sample Used to Remove Tc from DI Water

3.5. EXAFS Spectrum and Fit and Its Fourier Transform Obtained from a KMS-2 Sample Used to Remove Tc From a 7.8 M Na Ave Simulant ......................................................................... 3.7

3.6. Log Kd Values for the BFS 1 Getter Tested with an Initial [Tc] $\approx 53$ ppm in DI Water................. 3.8

3.7. Log Kd Values for the BFS 2 Getter Tested with an Initial [Tc] $\approx 53 \mathrm{ppm}$ in DI Water................ 3.9

3.8. Log Kd Values for the Tin Apatite Getter Tested with an Initial [Tc] $\approx 53 \mathrm{ppm}$ in DI Water. ....... 3.9

3.9. Log Kd Values for the BFS 1 Getter Tested with Various Tc Concentrations $(\mathrm{C} 1=5 \mathrm{ppm}$, $\mathrm{C} 2=27 \mathrm{ppm}, \mathrm{C} 3=53 \mathrm{ppm}$ ) $7.8 \mathrm{M}$ Na Solutions Made Without the Addition of Cr.....

3.10. Log Kd Values for the BFS 2 Getter Tested with Various Tc Concentrations $(\mathrm{C} 1=5 \mathrm{ppm}$, $\mathrm{C} 2=27 \mathrm{ppm}, \mathrm{C} 3=53 \mathrm{ppm}$ ) $7.8 \mathrm{M}$ Na Solutions Made Without the Addition of Cr.

3.11. Log Kd Values for the Tin Apatite Getter Tested with Various Tc Concentrations $(\mathrm{C} 1=5 \mathrm{ppm}, \mathrm{C} 2=27 \mathrm{ppm}, \mathrm{C} 3=53 \mathrm{ppm}) 7.8 \mathrm{M} \mathrm{Na}$ Solutions Made Without the Addition of $\mathrm{Cr}$

3.12. Log Kd Values for $\mathrm{Cr}$ for the Three Getter Materials in a Mix of Sodium Nitrate and Sodium Hydroxide.

3.13. Log Kd Values for Tc for the Three Getter Materials in a Mix of Sodium Nitrate and Sodium Hydroxide.

\section{Tables}

2.1. Simulant for LAW to be Used in Getters Tests

2.2. List and Origin of the Getter Materials Used in the Experiment ............................................... 2.3

3.1. Fitting Results for Tc Getter Samples................................................................................ 3.4

3.2. Fitting Parameters Used for the Tin Apatite Spectrum Given in Figure 3.4 …........................... 3.6

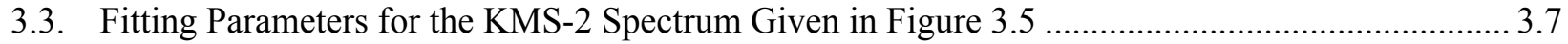




\subsection{Introduction and Background}

Technetium (Tc) is one of the most difficult radioactive contaminants to address at the U.S. Department of Energy (DOE) Hanford Site because of its complex chemical behavior in tank waste, limited incorporation in mid- to high-temperature immobilization processes (vitrification, steam reformation, etc.), and high mobility in subsurface environments. Currently, much of the technetium-99 $\left({ }^{99} \mathrm{Tc}, \mathrm{t}_{1 / 2}=213,000 \mathrm{y}\right)$ remains in the Hanford tanks and must be dispositioned in approved waste forms. Cast Stone, a cementitious grout, is one low-temperature waste form that is capable of immobilizing ${ }^{99} \mathrm{Tc}$. It has been selected as the preferred waste form for solidification of the Hanford Tank Waste Treatment and Immobilization Plant (WTP) secondary liquid effluents from process condensates and low-activity waste (LAW) melter off-gas caustic scrubber effluents. Due to the volatility of Tc at LAW vitrification melter temperatures, there is a potential for high Tc concentrations in the secondary off-gas scrubber waste streams. Cast Stone is also being evaluated, along with increasing the capacity of the baseline LAW vitrification facility, as a supplemental immobilization technology for immobilizing Hanford LAW. Using Cast Stone as a supplemental immobilization technology would also provide the necessary LAW treatment capacity to complete the tank waste cleanup mission in a timely and cost-effective manner. Based on preliminary studies of secondary waste simulants (Mattigod et al. 2011; Sundaram et al. 2011) and the general similarity of liquid secondary wastes to LAW, Cast Stone may be a worthy candidate for LAW immobilization.

At the Hanford Site the current plan is to dispose the immobilized low-activity waste (ILAW) and the solidified secondary wastes in the Integrated Disposal Facility (IDF) located at the Hanford site. Performance assessments (PAs) and risk assessments are used to evaluate the potential environmental impact from disposal of LAW forms. Past performance assessments and risk assessments (DOE 2012; Mann et al. 2001; Mann et al. 2003) which used diffusion-controlled release models for contaminants from grouts, show that releases from LAW disposal might not meet environmental protection standards over long periods of time. The effective diffusion coefficients that were used were taken from grout leaching literature available at the time and were not specific for the current formulation of Cast Stone. For ${ }^{99} \mathrm{Tc}$ the diffusion values used were $3.2 \times 10^{-10} \mathrm{~cm}^{2} / \mathrm{s}$ and $5.2 \times 10^{-9} \mathrm{~cm}^{2} / \mathrm{s}$ for Mann et al. $(2001,2003)$ and DOE (2012). From the risk assessment results from Mann et al. (2003) it was suggested that the ${ }^{99} \mathrm{Tc}$ diffusion value should be lower to meet groundwater protection standards likely to be used for the IDF. This statement is valid as long as other assumptions are retained in future IDF performance assessment projections.

As mentioned, effective diffusion coefficients used in the PA and risk assessments were based on diffusion values taken from grout leaching literature available at the time. Therefore, to investigate the potential behavior of Cast Stone disposed at the IDF, recent experiments at Pacific Northwest National Laboratory (PNNL) have used the current baseline recipe for Cast Stone to solidify several LAW and secondary waste simulants. The baseline Cast Stone recipe uses a dry blend mixture of Grade 100 or 120 blast furnace slag (47 wt\%), Class F fly ash (45 wt\%), and Type I/II Portland cement (8 wt\%). Monoliths of the final cured Cast Stone waste forms were then leached using up to three standard leaching protocols for time periods of 63 to more than 91 days and the results for Cast Stone with both LAW (Westsik JH Jr et al. 2013) and secondary waste (Mattigod et al. 2011) indicated that ${ }^{99} \mathrm{Tc}$ diffusivities were in the range of $5 \times 10^{-12}$ to $3 \times 10^{-10} \mathrm{~cm}^{2} / \mathrm{s}$. Given the results of Mann et al. (2003), it appears that the recently

measured range in effective diffusion coefficients for ${ }^{99} \mathrm{Tc}$ are within the range that might show acceptable groundwater protection. However, there is concern that the ${ }^{99} \mathrm{Tc}$ leach performance exhibited 
in these short-term laboratory tests may not account for longer-term re-oxidation of Tc in the Cast Stone as the reductants are depleted in the oxidizing environment of the Cast Stone (Serne et al. 2011). This is of concern because the oxidized Tc(VII) [pertechnetate] form is highly mobile in the subsurface environment compared with the less-mobile Tc(IV). Therefore, the retention of ${ }^{99} \mathrm{Tc}$ in the Cast Stone waste forms needs to be improved. One method of improving the performance of the Cast Stone waste forms is to add materials, known as getters, which selectively sequester the radionuclides.

A summary of getter literature was included in Appendix A of a previously published report (Qafoku et al. 2014). Briefly, the literature review identified several getters as having promising properties for Tc removal and sequestration, including nanoporous tin phosphates, Tin Apatite, and ground blast furnace slag (BFS). The study by Qafoku et al. (2014) also examined the effectiveness of using potassium metal sulfide (KMS-2), $\mathrm{SnCl}_{2}$, and tin(II) hydroxyapatite for Tc removal. The results showed that although most getters showed promising results in deionized (DI) water, their performance for Tc removal was mitigated when batch sorption experiments were performed in a highly caustic, high ionic strength LAW simulant. The present report aims to investigate the reasons for decreased Tc removal by the getter materials in the LAW simulant. Experiments performed here have investigated the impact of varying the total reduction capacity of the getters by adding a larger mass while keeping the solution volume constant and investigating the competitive effects of $\mathrm{Cr}(\mathrm{VI})$, another species that may compete with $\mathrm{Tc}$ for electrons. The experiments will aid in identifying the best Tc getter candidates that may eventually be incorporated into the Cast Stone production process.

The long-term performance of the getters as part of monolithic waste forms, which is currently unknown, must be evaluated (Pierce et al. 2010a). For example, BFS included in the Cast Stone dry blend mixture has been shown to be effective at reducing $\mathrm{Tc}(\mathrm{VII})$ to the less-mobile $\mathrm{Tc}(\mathrm{IV})$ oxidation state, resulting in improved retention of Tc in the Cast Stone as long as reducing conditions prevail. However, past experimental work has also demonstrated that the BFS getter-based waste forms may release $\mathrm{Tc}$ as a result of oxidation of $\mathrm{Tc}_{2} \mathrm{~S}_{7}$ and $\mathrm{TcO}_{2}$ in the presence of $\mathrm{O}_{2}$. One key tenet is that getters should not adversely affect the waste-form performance. Experimental work is required to determine the effectiveness of the various getter materials prior to their solidification in Cast Stone.

\subsection{Objectives and Report Organization}

The overall objective of this task is to improve the performance of the low-temperature waste form Cast-Stone. Current separated Tc disposition pathways typically involve recycling the Tc to the LAW treatment processes or sending it to HLW vitrification for immobilization in a glass waste form.

Alternative waste forms that do not have the Tc volatility issues associated with the vitrification processes are being sought for immobilization of Tc for storage and disposal. The objectives of our testing program are to 1) determine an acceptable formulation for the LAW Cast Stone waste form with getters, 2) demonstrate the robustness of the formulation in terms of Tc release diffusivities, and 3) provide Cast Stone contaminant release data for risk assessment evaluations. The specific objective for this part of the study was to investigate Tc getters performance under conditions relevant to those of the waste streams. A series of batch sorption experiments was conducted to address this objective. The experiments were conducted under strict anoxic conditions inside chambers with controlled atmosphere (in absence of air) to allow for a better estimation of getter performance in the absence of competing electron acceptors, such as $\mathrm{O}_{2}$. Efforts were also made to probe the nature of the solid phases formed as a result of Tc 
sequestration with getters and to probe the competition of Tc reduction with other easily reduced species in the LAW simulant. To summarize, the primary goals of the present experiments are:

1. To perform advanced characterization of the solid materials generated after prolonged contact with the various solutions in the report by Qafoku et al. (2014). This includes scanning electron microscopy/energy dispersive spectroscopy (SEM/EDS) and bulk x-ray absorption near-edge structure/extended x-ray absorption fine structure (XANES/EXAFS) analysis of the materials. The goal of these experiments was to examine the location of Tc on the surface of the reacted getter materials and to identify the oxidation state of the Tc species on the surface of the getter materials.

2. To investigate if a sufficient amount of material is present in the getter material to be able to reduce the Tc in solution. This experiment was conducted as a result of observations made by Qafoku et al (2014) where the increase in the getter-mass-to-solution-volume ratio led to faster and more effective removal of Tc from solution.

3. To examine the competing role of $\mathrm{Cr}$ and nitrate for $\mathrm{Tc}$ for removal by the getter from the LAW simulant. Because $\mathrm{Cr}$ can also be reduced from $\mathrm{Cr}$ (VI) to $\mathrm{Cr}$ (III), it is thought that $\mathrm{Cr}$ and nitrate may be mitigating Tc reduction and removal because it is more easily being reduced by the getter. A series of experiments examining the removal of $\mathrm{Tc}$ and $\mathrm{Cr}$ by getters was performed to see if both species are more easily removed when the other species is absent from the LAW simulant. 



\subsection{Technical Scope and Approach}

\subsection{Quality Assurance}

All research and development (R\&D) work at PNNL is performed in accordance with PNNL's Laboratory-level Quality Management Program, which is based on a graded application of NQA-1-2000, Quality Assurance Requirements for Nuclear Facility Applications, to R\&D activities. To ensure that all client quality assurance (QA) expectations were addressed, the QA controls of the Environmental Management Support Program (EMSP) QA program were also implemented for this work. The EMSP QA program consists of the EMSP Quality Assurance Plan (QA-EMSP-001) and associated QA-EMSP-numbered procedures that provide detailed instructions for implementing NQA-1-2000 for R\&D work.

The work described in this report was assigned the technology level "Applied Research" and was planned, performed, documented, and reported in accordance with Procedure QA-EMSP-1102, Scientific Investigation for Applied Research. All staff members contributing to the work received proper technical and quality assurance training prior to performing quality-affecting work.

\subsection{Solid State Characterization}

A suite of solid-state characterization analyses was performed on a set of Tc getters materials that resulted from a set of roughly 100-day batch tests performed by Qafoku et al. (2014). The characterization techniques were run to investigate the location and oxidation state of Tc on the getters. The solids were separated from the solution by mixing the material inside the $100 \mathrm{~mL}$ reaction vessels and adding the resulting suspension into $50 \mathrm{~mL}$ centrifuge tubes. After centrifuging, the supernatant liquid was decanted and additional slurry solution was added to the centrifuge tubes. This process was repeated until no more material was left in the $100 \mathrm{~mL}$ vial. After centrifugation, the getter material was left to dry at room temperature under anoxic conditions and subsamples were sent for solid phase characterization studies.

The first of those studies was SEM/EDS using a FEI Helios 600 NanoLab FIB-SEM. Operating conditions were typically $5 \mathrm{keV}$ or less for imaging and $20 \mathrm{keV}$ for EDS measurements. EDS spectra were collected using Oxford INCA software with a live count of 100 seconds with a typical dead time of 30\%. The second characterization technique was X-ray Absorption Fine Structure (XAFS) that was obtained at the Stanford Synchotron Radiation Lightsource. Incoming X-rays were monochromatized using a double crystal monochromator with $\mathrm{Si} 220$ crystals. The second crystal was detuned by $50 \%$ to reduce the harmonic content and the spectra were collected in fluorescence mode using a 100 pixel Ge detector. The fluorescence data were corrected for detector dead time using the software packages SixPack (Webb 2005) and Athena (Ravel et al. 2005). The XANES spectroscopy was convolved with a 1.8-2.0 eV Gaussian to match the resolution of the standard spectra. The Tc standard spectra used are $\mathrm{TcO}_{4}{ }^{-}, \mathrm{Tc}(\mathrm{IV})$ EDTA complex, and $\mathrm{Tc}_{2} \mathrm{~S}_{7}$. The XANES spectra were fit using a linear-combination fit with the locally written program 'fites,' which performs a non-linear least squares fit of the data (http://lise.lbl.gov/RSXAP). 


\subsection{LAW Simulant Preparation}

Some of the batch sorption experiments (details given in Section 2.4) were performed in the presence of a LAW simulant. One simulant was selected to represent the LAW tank wastes and was used in the batch experiments described above. This simulant was used in the LAW Cast Stone screening tests and was named "7.8 M Na Ave". This LAW simulant was selected to represent the LAW in tanks. This is the simulant used in the LAW Cast Stone screening tests that was named 7.8 M Na Ave [see Westsik et al. (2013) for more details]. The list of chemicals, added to the solution in descending order, is given in Table 2.1. The simulant was developed based on Hanford Tank Waste Operations Simulator (HTWOS) model runs to support the River Protection Project System Plan Revision 6 (Certa et al. 2011). As one of the outputs, the HWTOS model provides the feed vector to a supplemental immobilization facility over the course of the tank waste treatment mission. The resulting values for various anions and cations are also given in Table 2.1. It should be noted that undissolved solids remained when the solution preparation was complete. Based on notes taken during the preparation, the solid is more likely a Na-phosphate and/or Na-fluoride and small amounts of Ni salt (Ni-nitrate was added but did not completely dissolve). In this set of experiments the solids were removed through filtering with a $0.45 \mu \mathrm{m}$ Nalgene filter. For the set of experiments run in the absence of $\mathrm{Cr}, \mathrm{Na}_{2} \mathrm{Cr}_{2} \mathrm{O}_{7} \cdot 2 \mathrm{H}_{2} \mathrm{O}$ was not added.

Table 2.1. Simulant for LAW to be Used in Getters Tests

\begin{tabular}{|c|c|c|c|c|}
\hline Compound & $\begin{array}{c}\text { Amount, } \\
\text { g/L }\end{array}$ & $\begin{array}{c}\text { Waste } \\
\text { Constituent }\end{array}$ & $\begin{array}{c}\text { HTWOS Overall } \\
\text { Average, } \mathrm{mol} / \mathrm{L}\end{array}$ & $\begin{array}{c}\text { Theoretical } \\
\text { Concentration, } \\
\text { mmol// } \mathbf{L}^{(a)}\end{array}$ \\
\hline $\mathrm{Al}\left(\mathrm{NO}_{3}\right)_{3} \cdot 9 \mathrm{H}_{2} \mathrm{O}$ & 179.54 & $\mathrm{Al}$ & 0.48 & \\
\hline $\mathrm{KNO}_{3}$ & 5.17 & $\mathrm{~K}$ & 0.06 & \\
\hline $\mathrm{NaNO}_{2}$ & 60.80 & $\mathrm{Na}$ & 7.80 & \\
\hline $\mathrm{NaNO}_{3}$ & 88.70 & $\mathrm{Cl}$ & 0.06 & \\
\hline $\mathrm{Na}_{3} \mathrm{PO}_{4} \cdot 12 \mathrm{H}_{2} \mathrm{O}$ & 29.18 & $\mathrm{CO}_{3}$ & 0.43 & \\
\hline $\mathrm{Na}_{2} \mathrm{SO}_{4}$ & 18.95 & $\mathrm{~F}$ & 0.05 & \\
\hline $\mathrm{Na}_{2} \mathrm{CO}_{3}$ & 45.33 & $\mathrm{NO}_{2}$ & 0.88 & \\
\hline $\mathrm{NaF}$ & 2.07 & $\mathrm{NO}_{3}$ & 2.53 & \\
\hline $\mathrm{NaCl}$ & 3.85 & $\mathrm{PO}_{4}$ & 0.08 & \\
\hline $\mathrm{NaOH}(50 \%$ soln $)$ & 347.81 & $\mathrm{SO}_{4}$ & 0.13 & \\
\hline $\mathrm{NaC}_{2} \mathrm{H}_{3} \mathrm{O}_{2}$ & 4.91 & TOC Total & 0.12 & \\
\hline $\mathrm{Na}_{2} \mathrm{Cr}_{2} \mathrm{O}_{7} \cdot 2 \mathrm{H}_{2} \mathrm{O}$ & 4.96 & Free $\mathrm{OH}$ & 2.43 & \\
\hline $\mathrm{Pb}\left(\mathrm{NO}_{3}\right)_{2}$ & 0.13 & $\mathrm{Cd}$ & & 0.25 \\
\hline $\mathrm{Ni}\left(\mathrm{NO}_{3}\right)_{2} \bullet 6 \mathrm{H}_{2} \mathrm{O}$ & 1.49 & $\mathrm{Cr}$ & & 33.3 \\
\hline $\mathrm{Cd}\left(\mathrm{NO}_{3}\right)_{2} \bullet 4 \mathrm{H}_{2} \mathrm{O}$ & 0.08 & $\mathrm{~Pb}$ & & 0.40 \\
\hline $\begin{array}{l}\text { (a) The theoretic } \\
\text { compounds d }\end{array}$ & $\begin{array}{l}\text { centratio } \\
\text { ed in the }\end{array}$ & $\begin{array}{l}\text { he concentra } \\
\text { ure. }\end{array}$ & of the given metc & e added \\
\hline
\end{tabular}

\subsection{Batch Sorption Tests Method}

In a recent report by Qafoku et al. (2014) seven getters were tested to determine their effectiveness in removing Tc from solutions of 18.2 M $\mathrm{DI}$ water as well as a 7.8 M Na Ave simulant (see Section 2.3). The getters were chosen because they had previously been identified as candidates for the removal of $\mathrm{Tc}(\mathrm{VII})$ from waste solution. In this series of tests we have used three of these getters to examine the effect of the getter-mass-to-solution-volume ratio and the effect of $\mathrm{Cr}$ and nitrate in the $7.8 \mathrm{M}$ Na simulant on Tc removal. The three getters that have been used are BFS 1, BFS 2, and Tin Apatite and they were 
chosen do to the ability to perform these scoping studies with a large mass of readily available material. More information on these getters is given in Table 2.2 as well as in Qafoku et al. (2014).

Table 2.2. List and Origin of the Getter Materials Used in the Experiment

\begin{tabular}{llll}
\hline \multicolumn{1}{c}{ Getter } & \multicolumn{1}{c}{ Full Name } & \multicolumn{1}{c}{$\begin{array}{c}\text { Vendor Name (if } \\
\text { applicable) }\end{array}$} & $\begin{array}{c}\text { Reference } \\
\text { (if applicable) }\end{array}$ \\
\hline BFS 1 & Blast Furnace Slag 1 & Lafarge North America & \\
BFS 2 & Blast Furnace Slag 2 & Holcim (US) Inc. & \\
Tin Apatite & Tin(II) Apatite & & Duncan et al. (2008) \\
\hline
\end{tabular}

Batch sorption tests performed involved placing a given mass of getter material in contact with $100 \mathrm{~mL}$ of solution for periods up to one month with periodic solution sampling. Each test was conducted in a 250 - $\mathrm{mL}$ polytetrafluoroethylene (PTFE) bottle at room temperature $\left(\sim 22^{\circ} \mathrm{C}\right)$ in an anoxic chamber containing $\mathrm{N}_{2}$ with $\mathrm{H}_{2}(0.7 \%)$ to maintain anoxic conditions. Each sample was run in duplicate. Sampling occurred at nominally $0.2,1,3,6,9,12$, and 15 days of experimental time. Sampling consisted of pipetting $2 \mathrm{~mL}$ of solution from the reactor vial and filtering through a $0.2-\mu \mathrm{m}$ filter membrane. The volume removed during sampling was not replaced. Care was taken to ensure that none of the solid material was removed from the vial during sample collection. A 1-mL aliquot of the filtrate was taken and acidified with $20 \mu \mathrm{L}$ of Optima grade $70 \% \mathrm{HNO}_{3}$ for inductively coupled plasma-mass spectroscopy (ICP-MS) analysis for Tc and/or Cr concentration measurements. Details for individual batch tests are given in subsequent sections.

\subsubsection{The Effect of the Solid (mass) to Solution (volume) Ratio}

Batch sorption experiments were performed to study the effect of the solid-to-solution ratio on the Tc $\mathrm{K}_{\mathrm{d}}$ value. The tests previously conducted by Qafoku et al. (2014) were conducted at a 1:100 g/mL solid-to-solution ratio. The only exception was BFS 1; where one experiment was conducted with a solid-to-solution ration of 1:10 g/mL. In the present set of experiments, a 1:10 g/mL ratio for BFS 2 and Tin Apatite was also performed. To obtain this ratio, $10 \mathrm{~g}$ of the getter material was added to $100 \mathrm{~mL}$ of solution. A third ratio of $1: 20 \mathrm{~g} / \mathrm{mL}$, or 5 grams of solid material in $100 \mathrm{~mL}$ solution, was also conducted. Each test was conducted in both DI water and the $7.8 \mathrm{M} \mathrm{Na}$ Ave simulant. Samples were spiked with Tc concentrations that were ten times higher than those calculated in the HTWOS model runs (Certa et al. 2011). The higher concentrations ensured measurable Tc concentrations throughout the duration of the experiment. Desired concentrations were made by adding less than $1 \mathrm{~mL}$ of a concentrated $(>10,000 \mathrm{ppm})$ stock solution of $\mathrm{NaTcO}_{4}$ to the $100-\mathrm{mL}$ solution.

\subsubsection{Competing Effects of $\mathrm{Tc}$ and $\mathrm{Cr}$}

Batch experiments were performed to study the competitive effect of $\mathrm{Tc}$ and $\mathrm{Cr}$, which are both present in the LAW simulant and which are both capable of being reduced by the getter material. The experiments involved using the getter material in LAW simulants that did not contain either $\mathrm{Cr}$ or Tc. To accomplish this, a new batch of 7.8 M Na Ave simulant was prepared without the addition of $\mathrm{Cr}(\mathrm{VI})$. The solution was made by following the synthesis outlined in Section 2.3 but eliminating the addition of $\mathrm{Na}_{2} \mathrm{Cr}_{2} \mathrm{O}_{7} \cdot 2 \mathrm{H}_{2} \mathrm{O}$. No correction for total $\mathrm{Na}^{+}$was performed because the sodium dichromate adds a relatively small amount of sodium compared to the amount of $\mathrm{NaOH}$ used. For the solution used in the 
experiments performed in the absence of $\mathrm{Tc}$, the $\mathrm{Na}_{2} \mathrm{Cr}_{2} \mathrm{O}_{7} \cdot 2 \mathrm{H}_{2} \mathrm{O}$ was added to the solution but the solution was not spiked with Tc. Tests were run using the $7.8 \mathrm{M}$ Na Ave simulant (with or without $\mathrm{Cr}$ or $\mathrm{Tc}$ ) at a 1:100 g/mL getter-mass-to-solution ratio with $1 \mathrm{~g}$ of getter material used. The three getter materials used were BFS 1, BFS 2, and Tin Apatite. Three concentrations of $\mathrm{TcO}_{4}{ }^{-}$(pertechnetate) to be spiked into the $7.8 \mathrm{M}$ Na Ave simulant were $5.2,26$, and $52 \mathrm{mg} / \mathrm{L}$ as pertechnetate. Experiments were also run using the $7.8 \mathrm{M} \mathrm{Na}$ Ave simulant where the solutions were not spiked with Tc in order to monitor the removal of $\mathrm{Cr}$ by the getter. However, because the starting [Cr] was relatively high $(2,000 \mathrm{ppm})$ it was not possible to definitively monitor the removal of Tc in solution due to the errors associated with the analysis. Therefore, if more reliable data were to be obtained in the future, $[\mathrm{Cr}]$ should be closer to the scale used by $[\mathrm{Tc}](\sim 53 \mathrm{ppm})$. At these concentrations any trend related to $\mathrm{Cr}$ removal would be less ambiguous. Tables that include the concentration of Tc in the $7.8 \mathrm{M} \mathrm{Na}$ Ave simulant as a function of time are given in Appendix A.

Another experiment was also performed with the goal of examining if nitrate may also compete with Tc for electrons as it may be reduced to the nitrite ion or another nitrogen-containing species. Here we describe these experiments; however, we note that at the time of writing of this report, not all of the results are available. To begin, a starting solution similar to the $7.8 \mathrm{M} \mathrm{Na}$ Ave simulant but consisting of only $\mathrm{NaNO}_{3}$ and $\mathrm{NaOH}$ was used in these experiments. The solution was made by adding $347.81 \mathrm{~g}$ $\mathrm{NaOH}\left(50 \%\right.$ soln) and $296.25 \mathrm{~g} \mathrm{NaNO}_{3}$ and dissolving the mixture in a total volume of $1 \mathrm{~L}$ with DI water. This solution had a total $[\mathrm{Na}]$ equal to the original $7.8 \mathrm{M} \mathrm{Na}$ Ave simulant.

This set of batch experiments was conducted by making three different solutions from the starting solution and these new solutions were called A, B, and C. The solutions were made as follows:

A. Solution A was made by adding $77 \mathrm{mg} / \mathrm{L} \mathrm{Na}_{2} \mathrm{Cr}_{2} \mathrm{O}_{7} \cdot 2 \mathrm{H}_{2} \mathrm{O}$

B. Solution B was made by adding $52 \mathrm{mg} / \mathrm{L} \mathrm{Tc}$ from a concentrated (stock) $\mathrm{TcO}_{4}{ }^{-}$solution

C. Solution $\mathrm{C}$ was made with both $\mathrm{Cr}(\mathrm{VI})$ and $\mathrm{Tc}(\mathrm{VII})$ added at concentrations roughly 63-to-1 excess of $\mathrm{Cr}(\mathrm{VI})$ over $\mathrm{Tc}(\mathrm{VII})$ in terms of meq. Therefore, the solution was made by adding $4.96 \mathrm{~g} / \mathrm{L} \mathrm{Na}_{2} \mathrm{Cr}_{2} \mathrm{O}_{7} \cdot 2 \mathrm{H}_{2} \mathrm{O}$ and $52 \mathrm{mg} / \mathrm{L} \mathrm{Tc}$ as $\mathrm{TcO}_{4}{ }^{-}$.

As mentioned, at the time of writing, only some of the results from Solution A and B were available. Once they become available, a further experiment will be designed where a solution of $\mathrm{NaCl} / \mathrm{NaOH}$ instead of $\mathrm{NaNO}_{3} / \mathrm{NaOH}$ will be used as the background electrolyte. This set of batch sorption experiments should be able to isolate the effects of $\mathrm{Cr}$ and nitrate in terms of $\mathrm{Tc}$ removal from solution.

\subsubsection{Calculation of the Distribution Coefficient, $\mathrm{K}_{\mathrm{d}}$}

To quantify the effectiveness of the various getter materials, a series of batch sorption experiments was performed. The batch experiments consisted of tests that measured the removal of a particular solution species by a solid phase, referred to here as the "getter." The sorption mechanisms for this sorption removal may be through processes associated with adsorption, surface precipitation, oxidation-reduction, or incorporation of the species into the structure of a mineral. To quantify the effectiveness of this removal, the distribution coefficient, $\mathrm{K}_{\mathrm{d}}(\mathrm{mL} / \mathrm{g})$, was calculated by using the following equation: 


$$
K_{d}=\frac{c_{i, b l a n k}-c_{i}}{c_{i}} \times \frac{V_{s}}{m_{g}}
$$

where $\quad c_{i, \text { blank }}=$ the solution concentration of species $i$ in the blank solution (no solid getter present),

$c_{i}=$ the solution concentration of species i measured in the solution after a set contact time with the getter material,

$V_{s}=$ the volume of solution in $\mathrm{mL}$, and

$m_{g}=$ the mass of the getter material in grams.

\subsection{Liquid Phase Analyses}

Technetium-99 and Cr-52/53 analysis for the batch $\mathrm{K}_{\mathrm{d}}$ experiments was performed using ICP-MS and high-purity calibration standards to generate calibration curves, which was verified by continuing calibration during the analysis run. Dilutions (from $20 \times$ to $500 \times$ ) were made for each batch $\mathrm{K}_{\mathrm{d}}$ sample from the DI water tests and $(500 \times$ to $5000 \times)$ for analysis of the batch $\mathrm{K}_{\mathrm{d}}$ sample from the $7.8 \mathrm{M} \mathrm{Na}$ Ave simulant tests to investigate and correct for matrix interferences. The method used was PNNL-AGG-415 (PNNL 1998), which is quite similar to EPA Method 6020 (EPA 2000). 



\subsection{Results and Discussion}

\subsection{Solid Phase Characterization}

\subsubsection{SEM/EDS}

SEM was used to examine the morphology while EDS was used to investigate the distribution of Tc on the surface of the various Tc getter materials used in Qafoku et al. (2014). The various getter materials examined with SEM were Tin Apatite, BFS 1, BFS 2, Tin hydroxyapatite, and KMS-2. However, the SEM images from samples contacting the $7.8 \mathrm{M} \mathrm{Na}$ Ave simulant were inconclusive due to the large amount of $\mathrm{Na}$ from the simulant that was not sufficiently washed from the surface and due to the lack of Tc removed from solution. Therefore, we only show SEM images and associated EDS spectra from getters that were contacted with Tc in DI water. We note that the EDS results are qualitative so they only act as an indicator of the general location of Tc on the sample.

The SEM/EDS results can be divided into two types of samples: those where Tc is evenly distributed across the surface and those where Tc forms distinct phases on the getter surface. One sample where Tc seemed to evenly distribute across the surface was Tin Apatite (Figure 3.1). From the image and spectra the major elements expected from apatite (theoretical formula $\left[\mathrm{Ca}_{5}\left(\mathrm{PO}_{4}\right)_{3}(\mathrm{OH}, \mathrm{F}, \mathrm{Cl})\right]$ ) are seen along with peaks from Tc. The location of these peaks seem to be evenly distributed across the apatite surfaces; however, there does not seem to be a distinct morphology associated with the presence of Tc which would aid in identifying the phase responsible for Tc sequestration. The only other Tc getter material that was examined where Tc was noticeable in the EDS spectra was BFS 2 (Figure 3.2). In this image and corresponding spectra, the Tc seems to be sequestered into an unidentified phase and not evenly distributed across the surface. Um et al. (2013) have identified the phase in BFS with the highest reductive capacity as a $\mathrm{CaS}$ phase (Oldhamite) and this may be the Tc-rich phase located in the micrograph. There was no definitive finding of Tc on the surface of BFS 1. Lastly, it was difficult to deconvolute the Tc peak from the S peak. Because $\mathrm{S}$ is a major component of KMS-2, the EDS spectra were inconclusive. 


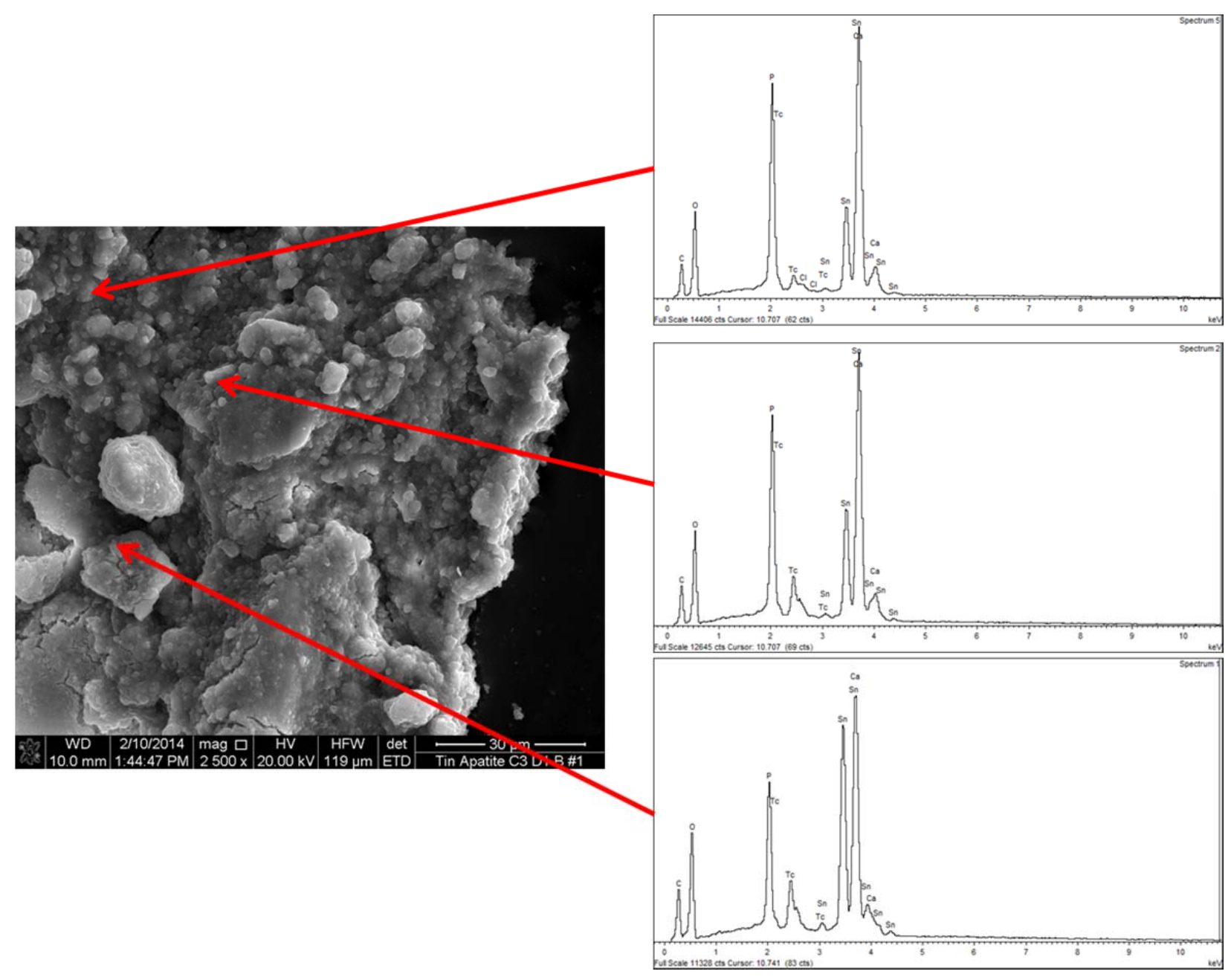

Figure 3.1. SEM/EDS Results for a Tin Apatite Sample Used in a DI Water Experiment for Tc Removal 


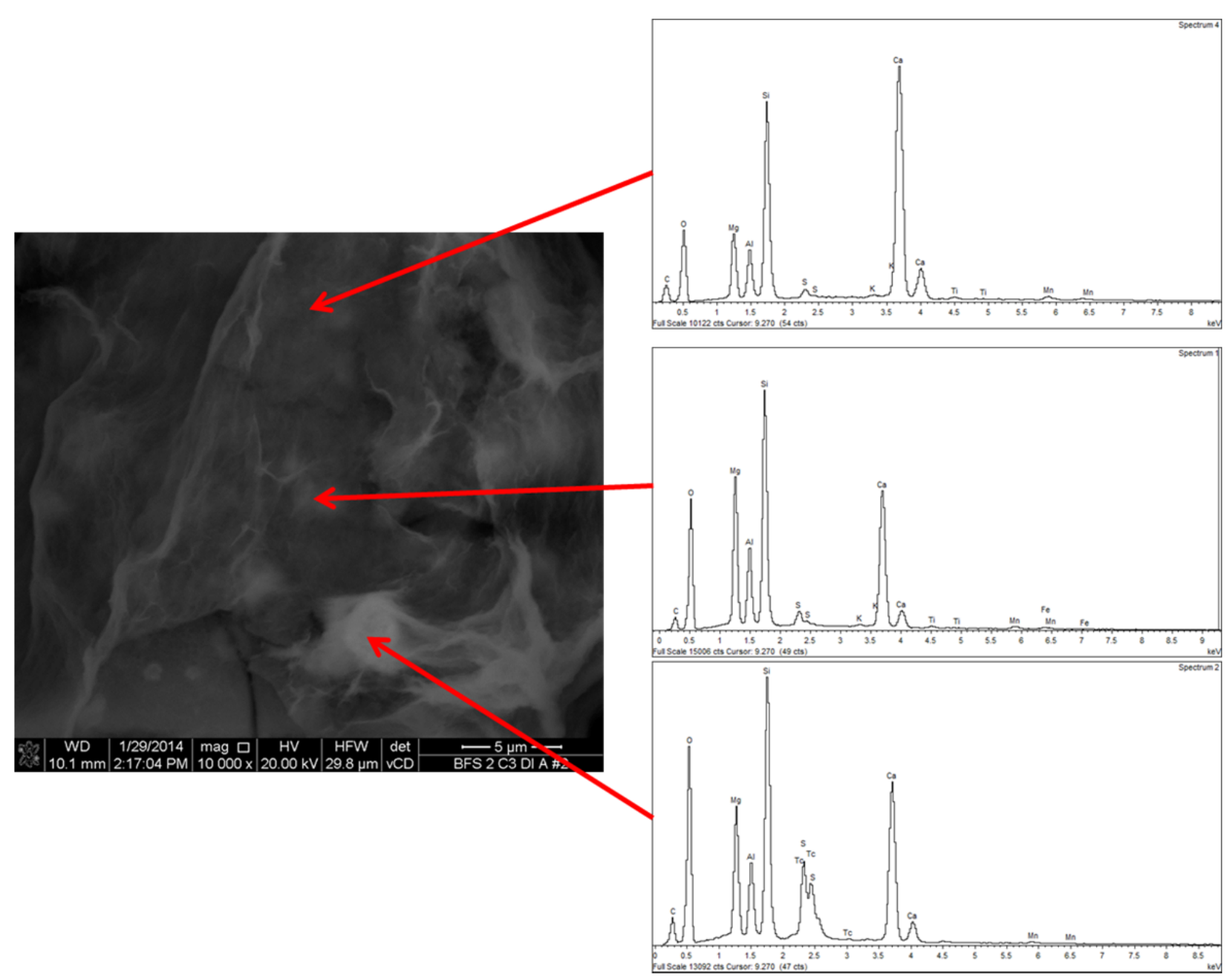

Figure 3.2. SEM/EDS Results for a BFS 2 Sample Used in a DI Water Experiment for Tc Removal

\subsubsection{XANES}

The Tc XANES spectra for four different samples created by Qafoku et al. (2014) and fits for each sample are given in Figure 3.3 while the fitting results are given in Table 3.1. With the exception of Sn-HA, the standard spectra fit the sample spectra well. Three standard spectra were used to model different potential local environment for Tc. The $\mathrm{TcO}_{4}{ }^{-}$standard represents $\mathrm{TcO}_{4}{ }^{-}$, the $\mathrm{Tc}(\mathrm{IV}) \mathrm{EDTA}$ standard represents Tc(IV) coordinated by oxygen atoms in a distorted octahedral environment similar to what one would expect for $\mathrm{Tc}(\mathrm{IV})$ sorbed to a mineral surface, and $\mathrm{Tc}_{2} \mathrm{~S}_{7}$ represents of $\mathrm{Tc}(\mathrm{IV})$ coordinated by sulfide and disulfide ligands. It should be noted that $\mathrm{Tc}_{2} \mathrm{~S}_{7}$ is better written as $\mathrm{Tc}_{2} \mathrm{~S}\left(\mathrm{~S}_{2}\right)_{3}$ and the ligands are primarily mixed monosulfide and disulfide groups rather than sulfide groups. The values in Table 3.1 may be interpreted as follows: $\mathrm{TcO}_{4}{ }^{-}$quantifies the $\mathrm{Tc}$ (VII) in the sample; Tc(IV)EDTA quantifies Tc(IV) coordinated by oxygen atoms, especially Tc(IV) sorbed to mineral surfaces; and $\mathrm{Tc}_{2} \mathrm{~S}_{7}$ quantifies $\mathrm{Tc}(\mathrm{IV})$ coordinated by sulfur atoms, as either sulfide or disulfide. 
Table 3.1. Fitting Results for Tc Getter Samples ${ }^{(a)}$. The numbers in parentheses are the standard deviations of the contribution of that component for the last digit; $p$ is the probability that the improvement of the fit, when this standard is included, is due to random error.

\begin{tabular}{llcccccc}
\hline \multicolumn{1}{c}{ Sample } & Solution & $\mathbf{T c O}_{\mathbf{4}}^{-}$ & $\mathbf{p}^{\mathbf{( b )}}$ & $\mathbf{T c}(\mathbf{I V})$ EDTA & $\mathbf{p}$ & $\mathbf{T c}_{\mathbf{2}} \mathbf{S}_{\mathbf{7}}$ & $\mathbf{p}$ \\
\hline Tin Apatite & DI water & $0.05(3)$ & 0.123 & $0.95(4)$ & $<0.001$ & $0.00(7)$ & 1 \\
BFS 2 & DI water & $0.90(1)$ & $<0.001$ & $0.10(2)$ & $<0.001$ & $0.00(2)$ & 1 \\
KMS-2 & 7.8 M Na Ave & $0.09(2)$ & 0.002 & $0.00(4)$ & 1 & $0.91(5)$ & $<0.001$ \\
Sn-HA & 7.8 M Na Ave & $0.21(4)$ & $<0.001$ & $0.13(6)$ & 0.065 & $0.66(8)$ & $<0.001$ \\
\hline
\end{tabular}

(a) The numbers in parentheses are the standard deviations of the contribution of that component

(b) $\mathrm{p}$ is the probability that the improvement of the fit, when this standard is included, is due to random error.

The XANES spectrum for Tin Apatite shows a good fit except at the very top of the edge ( $\sim 21070 \mathrm{eV})$, but the composition of the sample can be accurately determined from the XANES linear-combination fit. This slight mismatch at the edge suggests that the local environment of Tc is somewhat different from the local environment of Tc in Tc(IV)EDTA. However, the fit shows that only one Tc species, Tc(IV) coordinated by oxygen atoms in a distorted octahedral manner, contributes significantly to the XANES spectrum for Tin Apatite. Neither $\mathrm{TcO}_{4}{ }^{-}$nor $\mathrm{Tc}_{2} \mathrm{~S}_{7}$ contribute significantly. Although their contributions are non-zero, the large p-values for these components mean that these contributions may not be statistically significant. The XANES spectrum for BFS 2 shows a good agreement between the data and the fit is excellent, so the composition of the sample can be accurately determined from the XANES fit. This sample largely consists of $\mathrm{TcO}_{4}{ }^{-}$with a small contribution from Tc(IV). The XANES spectrum for KMS-2 shows a fit that is in excellent agreement with the data. Therefore, the composition of the sample can be accurately determined from the XANES fit. This sample consists primarily of $\mathrm{Tc}(\mathrm{IV})$ sulfide species and some $\mathrm{TcO}_{4}{ }^{-}$. The other $\mathrm{Tc}(\mathrm{IV})$ standard does not contribute significantly to the fit. Finally, the XANES spectrum for Sn-hydroxyapatite shows a poor fit where the numerical results are not reliable. Nevertheless, the fit shows that Tc is mainly present as reduced species. At most, $20 \%$ of the Tc is present as $\mathrm{TcO}_{4}{ }^{-}$. Because of the poor quality of the fit, the species present cannot be fully assigned. 

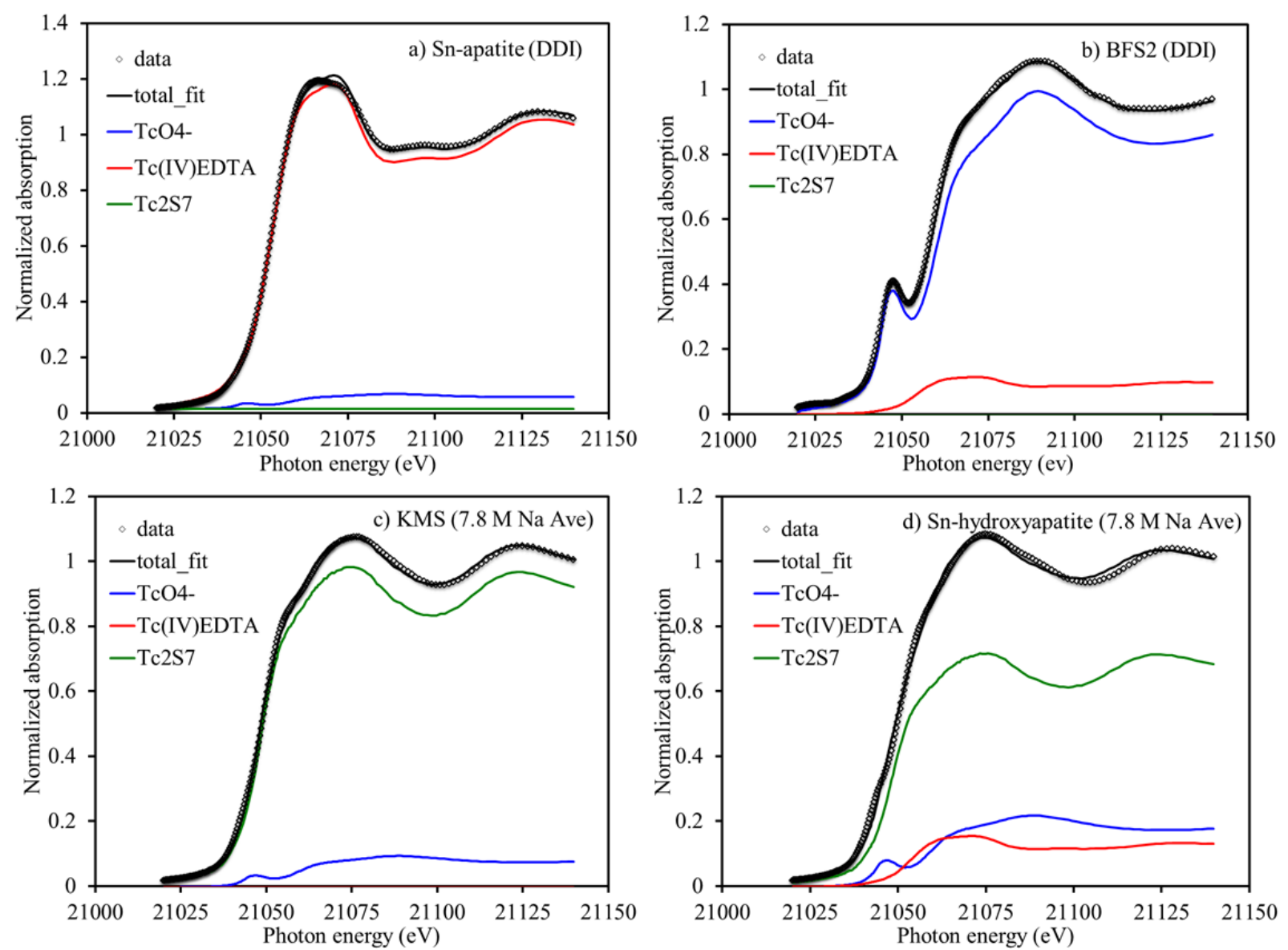

Figure 3.3. XANES Spectrum and Fit for Sample a) Sn-apatite, b) BFS 2, c) KMS-2, d) Tin Hydroxyapatite. The contribution of each component to the total fit is shown in color.

\subsubsection{EXAFS}

The X-ray absorption region just above the edge, given in Figure 3.3, contained features that were used to probe the extended x-ray absorption fine structure (EXAFS) for Tin Apatite in DI water and KMS-2 present in the $7.8 \mathrm{M} \mathrm{Na}$ Ave simulant. The spectrum for Tin Apatite is given in Figure 3.4 and the corresponding fitting parameters are given in Table 3.2. The table also calls out the parameters $\mathrm{S}_{0}{ }^{2}$ (the amplitude reduction factor) and the energy shift $(\Delta \mathrm{E})$ that are both used to calculate $\chi$ for the EXAFS fits in Figure 3.4. More information on the fitting method is given by Lukens et al. (2002). Both O and Tc neighbors contribute significantly to the spectrum as shown by the very low p-values. Inclusion of a shorter Tc-O distance (due to $\mathrm{TcO}_{4}^{-}$, for example) does not improve the spectrum. The data are consistent with $\mathrm{TcO}_{2} \cdot 2 \mathrm{H}_{2} \mathrm{O}$ (Lukens et al. 2002). There is no evidence for Tc-Sn or Tc-Ca interactions. From this data, Tin Apatite functions as a simple reductant of $\mathrm{TcO}_{4}{ }^{-}$. The spectrum contains no evidence of Tc incorporation into the lattice of any solid oxide other than $\mathrm{TcO}_{2} \cdot 2 \mathrm{H}_{2} \mathrm{O}$. 

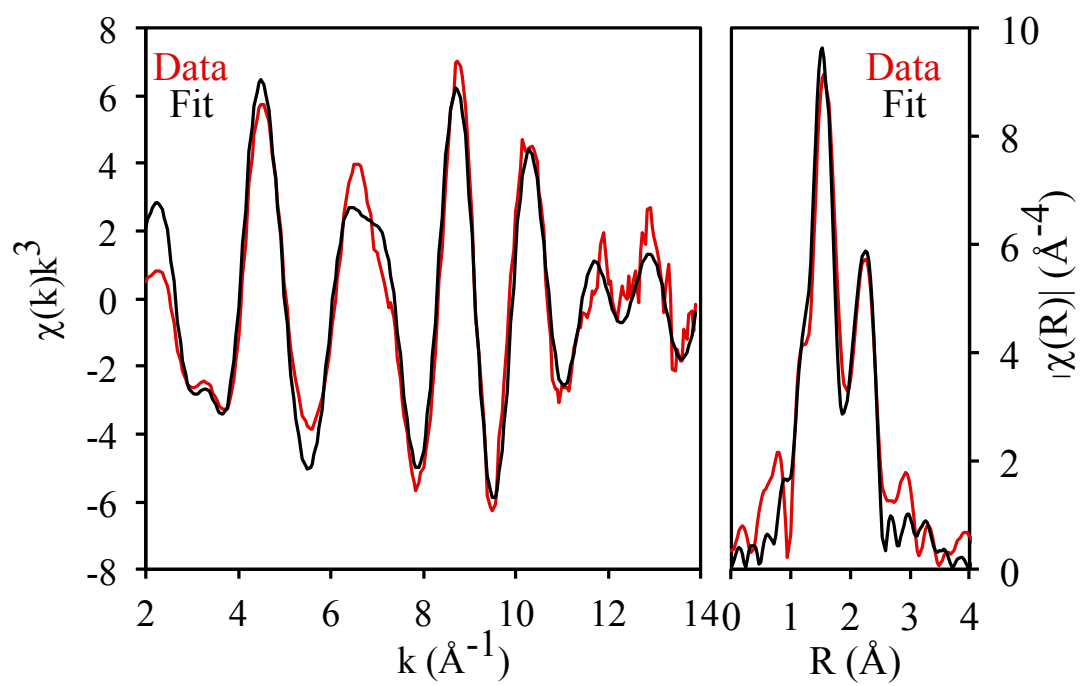

Figure 3.4. EXAFS Spectrum (red) and Fit (black) (left panel) and Its Fourier Transform (right panel) Obtained from a Tin Apatite Sample Used to Remove Tc from DI Water

Table 3.2. Fitting Parameters Used for the Tin Apatite Spectrum Given in Figure $3.4^{(\mathrm{a})}$

\begin{tabular}{cccccc}
\hline Neighbor & \# of Neighbors & Distance $(\AA)$ & $\sigma^{2}\left(\AA^{2}\right)$ & $\mathrm{p}$ & $\mathrm{TcO}_{2} \cdot 2 \mathrm{H}_{2} \mathrm{O}$ \\
\hline$O^{(\mathrm{b})}$ & 6 & $2.031(7)$ & $0.0055(6)$ & $<0.001$ & $4 \mathrm{O}$ at $2.02 \AA$ \\
$T c$ & 2 & $2.556(7)$ & $0.0063(5)$ & $<0.001$ & $2 \mathrm{Tc}$ at $2.57 \AA$ \\
\hline
\end{tabular}

(a) $\mathrm{S}_{0}^{2}=0.9$ (fixed), $\Delta \mathrm{E}=4(1) \mathrm{eV}$.

(b) (Lukens et al. 2002).

(c) Distance is twice the Tc-O distance.

The spectrum and fit for KMS-2 are also good. All scattering neighbors contribute significantly to the spectrum as shown by the very low p-values. The data are consistent with Tc-S and Tc-Tc distances and consistent with the presence of $\mathrm{Tc}_{2} \mathrm{~S}_{7}$. However, there is another phase with a very long Tc-O distance present. It is not entirely clear what this other phase is, but it is not $\mathrm{TcO}_{2} \cdot 2 \mathrm{H}_{2} \mathrm{O}$ since the Tc-O distance is too long. The scattering atom could be something other than $\mathrm{O}$, which would make the distance somewhat different. More likely, this sample is slightly hydrolyzed $\mathrm{Tc}_{2} \mathrm{~S}_{7}$, and the long Tc-O distance is a consequence of additional coordination with $\mathrm{S}$ in $\mathrm{Tc}_{2} \mathrm{~S}_{7}$. At any rate, KMS-2 appears to act as a source for sulfide to reduce $\mathrm{TcO}_{4}{ }^{-}$and sorb it as $\mathrm{Tc}_{2} \mathrm{~S}_{7}$. 


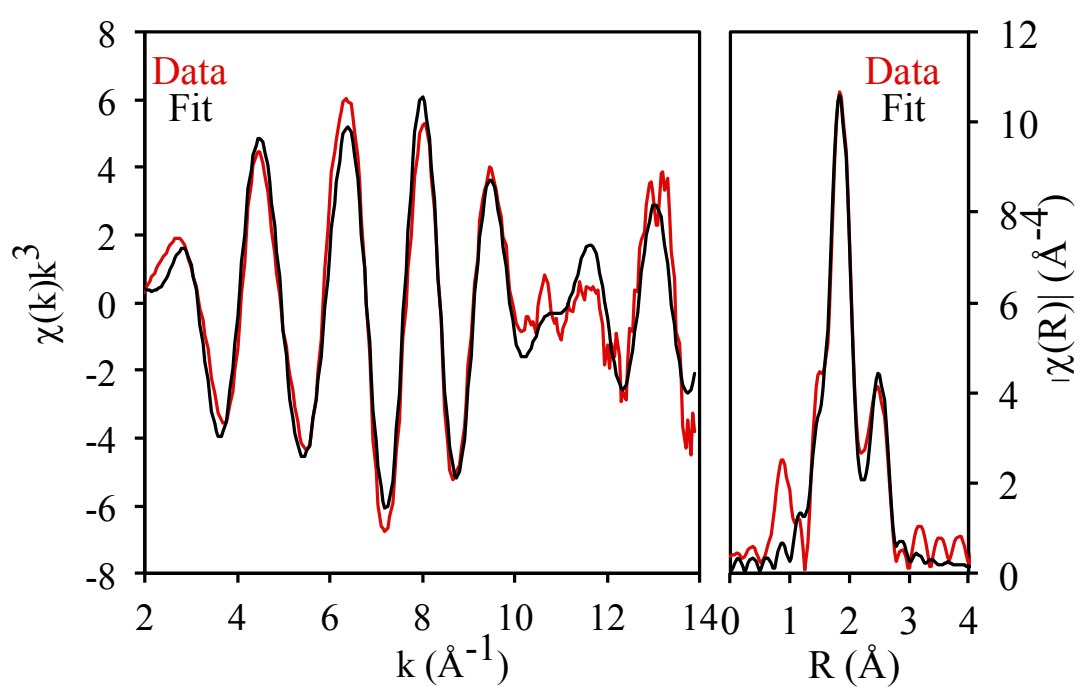

Figure 3.5. EXAFS Spectrum (red) and Fit (black) (left panel) and Its Fourier Transform (right panel) Obtained from a KMS-2 Sample Used to Remove Tc From a 7.8 M Na Ave Simulant

Table 3.3. Fitting Parameters for the KMS-2 Spectrum Given in Figure $3.5^{(\mathrm{a})}$

\begin{tabular}{ccccccc}
\hline Neighbor & \# of Neighbors & Mol fraction & Distance $(\AA)$ & $\sigma^{2}\left(\AA^{2}\right)$ & $\mathrm{p}$ & $\mathrm{Tc}_{2} \mathrm{~S}_{7}{ }^{(\mathrm{b})}$ \\
\hline$O$ & 6 & $0.3(1)$ & $2.19(1)$ & $0.001(2)$ & 0.002 & -- \\
$S$ & 7 & $0.7(1)$ & $2.35(2)$ & $0.011(2)$ & $<0.001$ & $7.4 \mathrm{~S}$ at $2.39 \AA$ \\
$T c$ & 2 & $0.7(1)$ & $2.79(1)$ & $0.006(1)$ & $<0.001$ & $1.8 \mathrm{Tc}$ at $2.77 \AA$ \\
\hline
\end{tabular}

(a) $\mathrm{S}_{0}^{2}=0.9$ (fixed), $\Delta \mathrm{E}=4(1) \mathrm{eV}$.

(b) (Lukens et al. 2005).

\subsection{Effect of Changing Ratio}

In the previous set of experiments by Qafoku et al (2014), the getter-mass-to-solution-volume ratio was fixed at 1:10 except for one experiment for BFS 1, which was run at a ratio of 1:100. In DI water the 15-day $\log \left(\mathrm{K}_{\mathrm{d}}\right)$ value changed from 1.2 for the $1: 100$ experiment to 6.8 for the 1:10 experiment, indicating a non-linear relationship between getter mass and Tc removal. However, there did not seem to be any enhancement when a similar change in the ratio was used in the presence of the $7.8 \mathrm{M} \mathrm{Na}$ Ave simulant. Nevertheless, these results suggested that Tc removal could be enhanced, both in total Tc removal and kinetics, through the simple addition of more getter. Therefore, to demonstrate this theory experimentally, a series of experiments was performed to investigate if, by changing the getter-mass-to-solution-volume ratio, an enhancement in Tc removal could be achieved for any of the other getters.

The experimental results for samples in DI water, presented in Figure 3.6, Figure 3.7, and Figure 3.8, indicate that sequentially more $\mathrm{Tc}$ is removed from solution when the ratio decreases (i.e., more getter material per solution volume). The increase in getter mass in the $7.8 \mathrm{M} \mathrm{Na}$ Ave simulant did not lead to an enhanced removal of Tc. The results will not be given in this section but can be referenced in the 
Appendix. For BFS 1 (Figure 3.6) the results for the 1:10 ratio were compared to those obtained from Qafoku et al. (2014) by running the experiment in the same conditions to ensure that similar results were obtained in this round of testing compared to the previous round of testing. For the other results, it is seen that as the amount of mass in the experiment is decreased, there is a corresponding decrease in the $\mathrm{K}_{\mathrm{d}}$ value. For the 1:20 ratio conditions, the $\mathrm{K}_{\mathrm{d}}$ value seems to plateau near the "maximum" removal value represented by the solid black line but it takes about 5 days longer to reach this value compared to the experiment with the 1:10 ratio. The almost complete removal of Tc from solution was not observed by Qafoku et al. (2014) when a 1:10 getter-mass-to-solution-volume ratio was used.

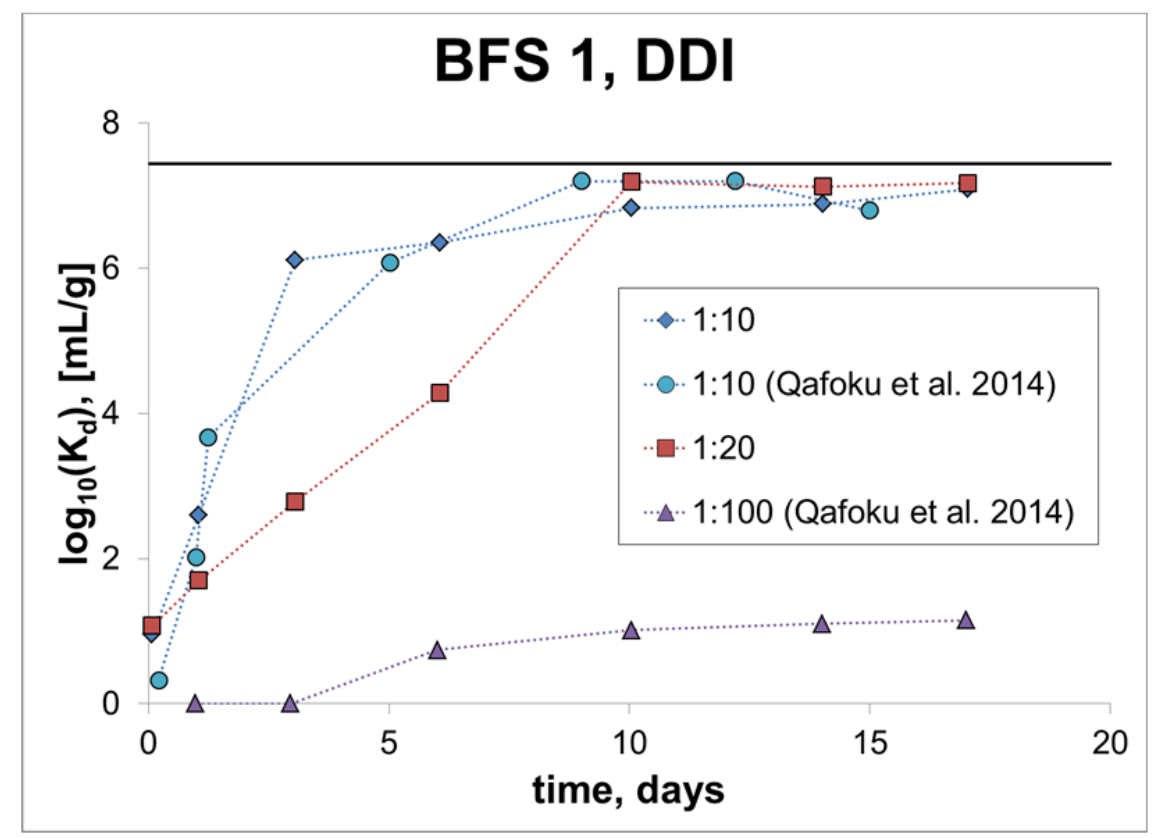

Figure 3.6. $\quad$ Log $K_{d}$ Values for the BFS 1 Getter Tested with an Initial [Tc] $\approx 53 \mathrm{ppm}$ in DI Water. The getter-mass-to-solution-volume is given in the legend and compared to values obtained with BFS 1 from Qafoku et al. (2014). Kd values have been corrected for volume lost during the periodic sampling. The solid black line is there to lead the eye and indicates a nominal $100 \%$ removal of Tc from solution.

The results for BFS 2 and Tin Apatite are presented in Figure 3.7 and Figure 3.8, respectively. Similar trends are observed where increasing the mass of the getter material increases the rate of removal of Tc from solution. For BFS 2, the addition of more mass of material leads to a faster removal of Tc from solution. Both the 1:10 and 1:20 ratio lead to an almost complete removal of Tc from solution within 20 days. This was not the case observed by Qafoku et al. (2014) where a mere 50\% Tc removal was observed in similar experimental conditions. On the other hand, results for Tin Apatite seem to be independent of the getter-mass-to-solution-volume ratios used in these sets of experiments. However, the rate of Tc removal seems to be enhanced by the increase in Tin Apatite mass in solution where nearly complete removal is observed by 10 days of reaction time. 


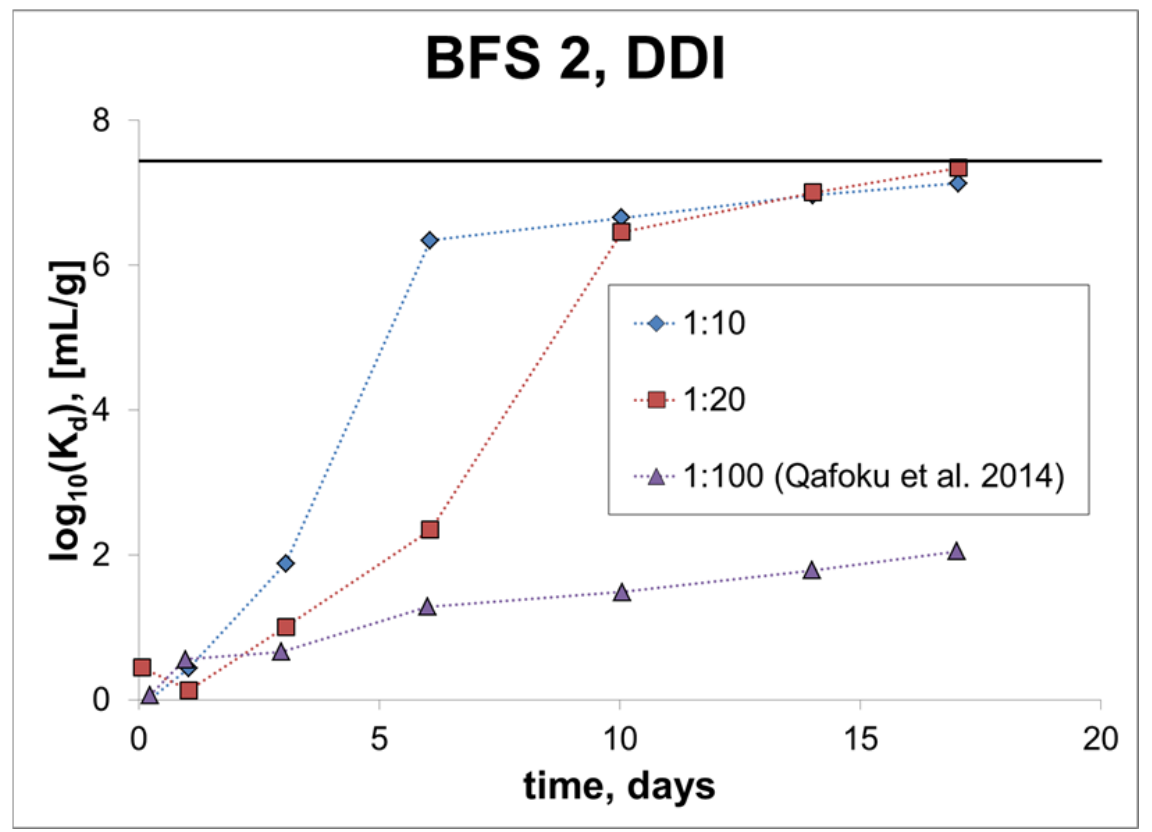

Figure 3.7. $\quad$ Log $\mathrm{K}_{d}$ Values for the BFS 2 Getter Tested with an Initial [Tc] $\approx 53 \mathrm{ppm}$ in DI Water. The getter-mass-to-solution-volume is given in the legend and compared to values obtained with BFS 2 from Qafoku et al. (2014). Kd values have been corrected for volume lost during the periodic sampling. The solid black line is there to lead the eye and indicates a nominal $100 \%$ removal of Tc from solution.

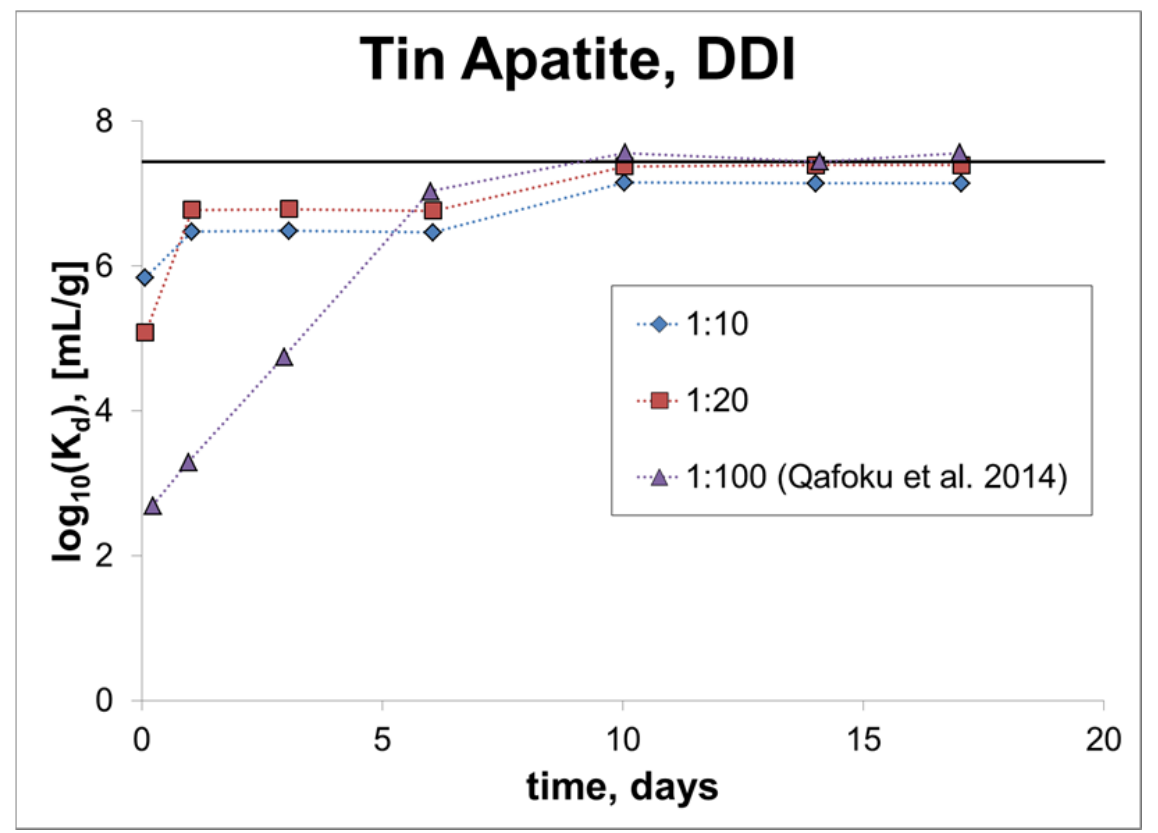

Figure 3.8. $\quad$ Log $\mathrm{K}_{\mathrm{d}}$ Values for the Tin Apatite Getter Tested with an Initial [Tc] $\approx 53 \mathrm{ppm}$ in DI Water. The getter-mass-to-solution-volume is given in the legend and compared to values obtained with Tin Apatite from Qafoku et al. (2014). Kd values have been corrected for volume lost during the periodic sampling. The solid black line is there to lead the eye and indicates a nominal $100 \%$ removal of Tc from solution. 


\subsection{Competition of Tc and Cr on Getter Effectiveness}

Cr may directly compete with Tc for sorption sites and/or electrons as it can be reduced from $\mathrm{Cr}(\mathrm{VI})$ to $\mathrm{Cr}(\mathrm{III})$. This set of experiments involved making a new batch of 7.8 $\mathrm{M}$ Na Ave simulant without the addition of $\mathrm{Cr}(\mathrm{VI})$ as $\mathrm{Na}_{2} \mathrm{Cr}_{2} \mathrm{O}_{7} \cdot 2 \mathrm{H}_{2} \mathrm{O}$. The three getter materials that were used were BFS 1 (Figure 3.9), BFS 2 (Figure 3.10), and Tin Apatite (Figure 3.11). For all three getter materials, the results are essentially the same. They indicate that the removal of Tc is enhanced in the absence of $\mathrm{Cr}$ and that the $\log \left(\mathrm{K}_{\mathrm{d}}\right)$ values, which range from 2 to 3 for all getters, are largely independent of the initial Tc concentration in solution. The results are promising because they indicate that $\mathrm{Cr}$, with a concentration near 2,000 ppm in the 7.8 M Na Ave simulant, may be a component responsible for a reduced effectiveness of Tc removal by the getters.

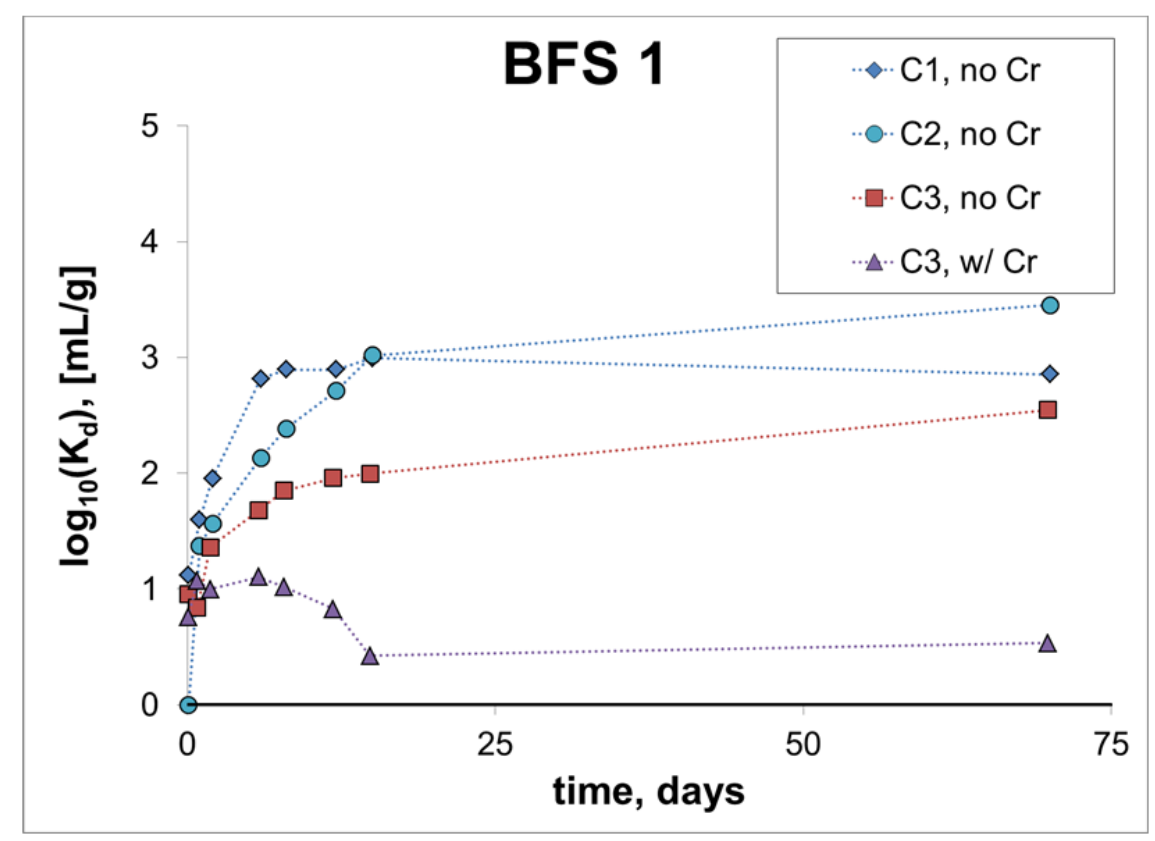

Figure 3.9. $\quad$ Log $\mathrm{K}_{\mathrm{d}}$ Values for the BFS 1 Getter Tested with Various Tc Concentrations $(\mathrm{C} 1=5 \mathrm{ppm}, \mathrm{C} 2=27 \mathrm{ppm}, \mathrm{C} 3=53 \mathrm{ppm}) 7.8 \mathrm{M} \mathrm{Na}$ Solutions Made Without the Addition of $\mathrm{Cr}$. The getter-mass-to-solution-volume ratio is $1: 100$. Kd values have been corrected for volume lost during the periodic sampling. 


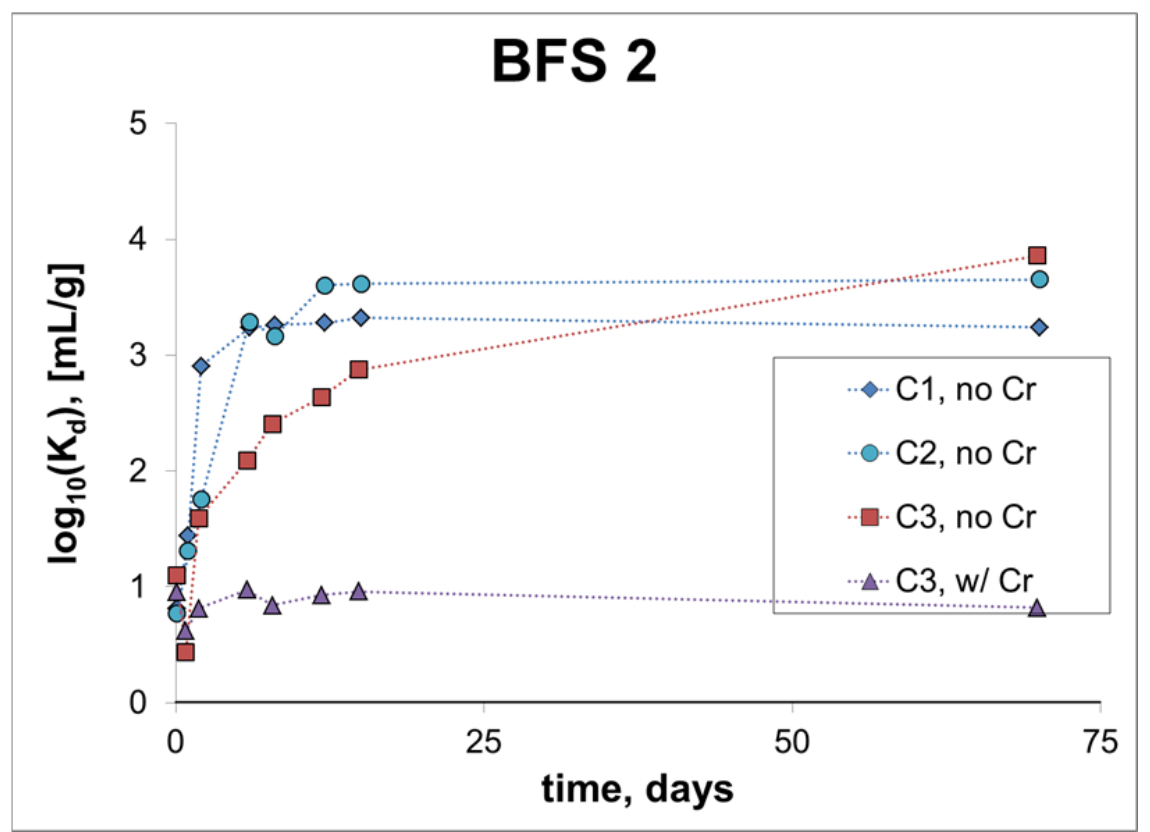

Figure 3.10. $\log \mathrm{K}_{\mathrm{d}}$ Values for the BFS 2 Getter Tested with Various Tc Concentrations $(\mathrm{C} 1=5 \mathrm{ppm}, \mathrm{C} 2=27 \mathrm{ppm}, \mathrm{C} 3=53 \mathrm{ppm}) 7.8 \mathrm{M}$ Na Solutions Made Without the Addition of $\mathrm{Cr}$. The getter-mass-to-solution-volume ratio is 1:100. Kd values have been corrected for volume lost during the periodic sampling.

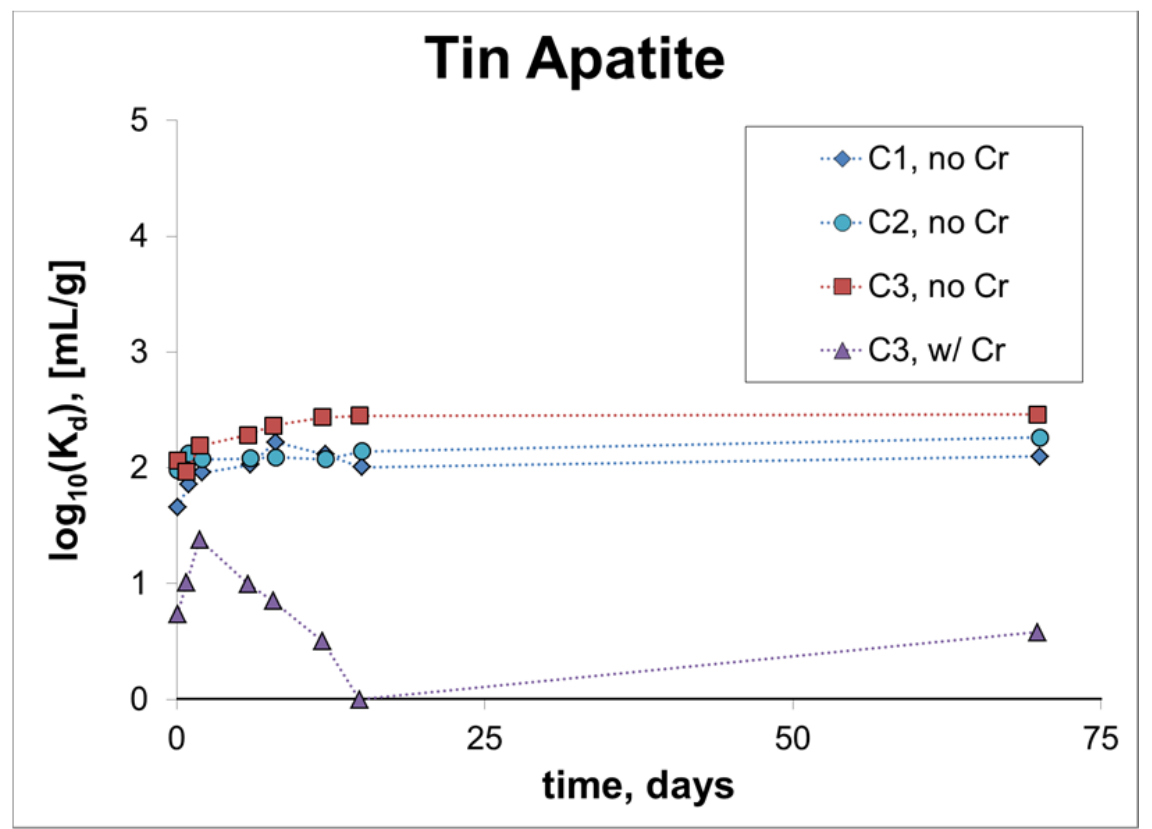

Figure 3.11. $\log \mathrm{K}_{\mathrm{d}}$ Values for the Tin Apatite Getter Tested with Various Tc Concentrations $(\mathrm{C} 1=5 \mathrm{ppm}, \mathrm{C} 2=27 \mathrm{ppm}, \mathrm{C} 3=53 \mathrm{ppm}) 7.8 \mathrm{M}$ Na Solutions Made Without the Addition of $\mathrm{Cr}$. The getter-mass-to-solution-volume ratio is 1:100. Kd values have been corrected for volume lost during the periodic sampling. 
Results for the removal of $\mathrm{Cr}$ from the $\mathrm{NaNO}_{3} / \mathrm{NaOH}$ solution are given in Figure 3.12 while the results for the removal of Tc from this solution are given in Figure 3.13. From Figure 3.12 it is seen that BFS 1 and BFS 2 removed Cr concentrations in solution from the starting $28 \mathrm{ppm}$ to levels below the estimated quantitation limit (EQL) $(0.208 \mathrm{ppm})$ in roughly 6 days of contact. On the other hand, Tin Apatite had a near-instantaneous removal of $\mathrm{Cr}$ but the levels in solution grew to roughly $0.5 \mathrm{ppm}$ $\left(\log \left(\mathrm{K}_{\mathrm{d}}\right)=3.8\right)$ and remained at that level throughout the experiment. For the removal of Tc from the $\mathrm{NaNO}_{3} / \mathrm{NaOH}$ solution (Figure 3.13), the results show BFS 1 and BFS $2 \log \left(\mathrm{K}_{\mathrm{d}}\right)$ values near 4 at the end of the 16-day experiment. Though the extent of removal for BFS 1 and BFS 2 are roughly equal at the end of the experiment, the rate of removal of Tc using BFS 2 is faster than BFS 1 . The $\log \left(\mathrm{K}_{\mathrm{d}}\right)$ values for Tin Apatite $(\sim 2.5)$ are slightly less than the values given by BFS 1 and BFS 2 and this value remains constant from six to sixteen days of contact. At the time of writing, there is no data for solution aliquots taken before 6 days of contact but the samples are available and results should be available at a later date.

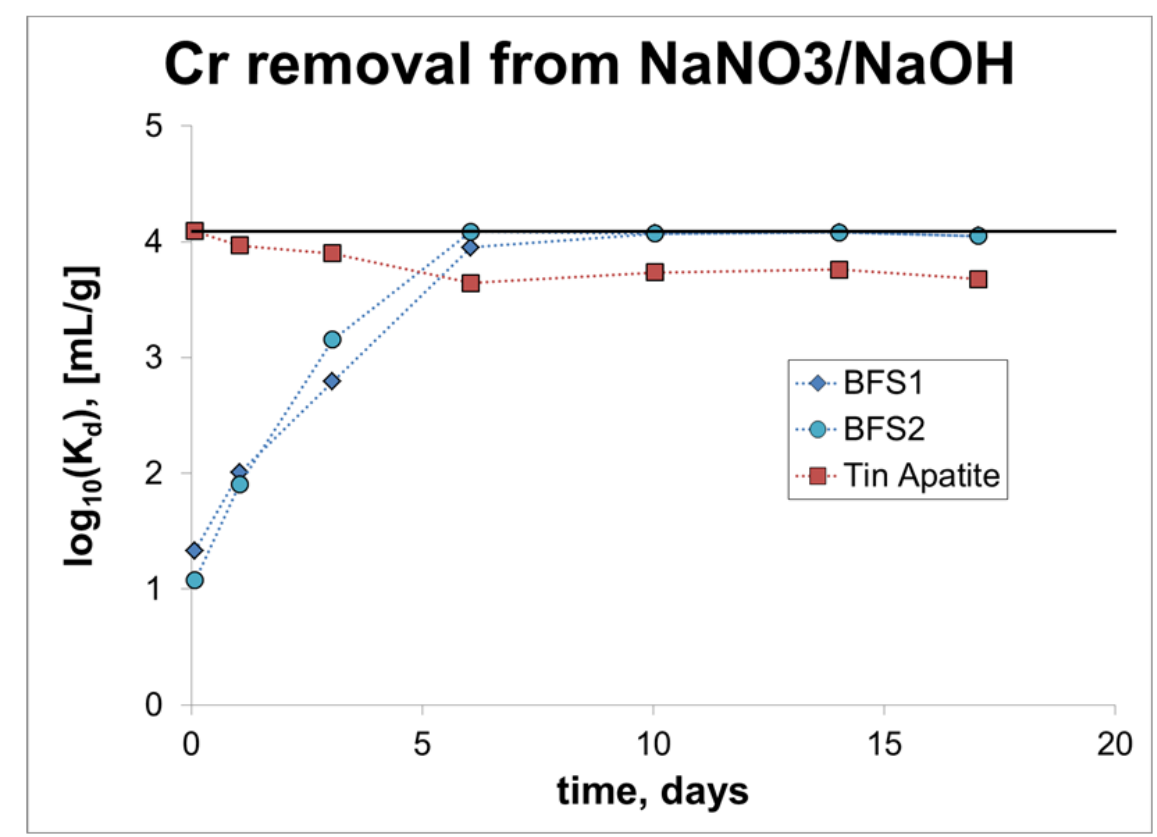

Figure 3.12. $\log \mathrm{K}_{\mathrm{d}}$ Values for $\mathrm{Cr}$ for the Three Getter Materials in a Mix of Sodium Nitrate and Sodium Hydroxide. The getter-mass-to-solution-volume ratio is 1:100. $\mathrm{K}_{\mathrm{d}}$ values have been corrected for volume lost during the periodic sampling. 


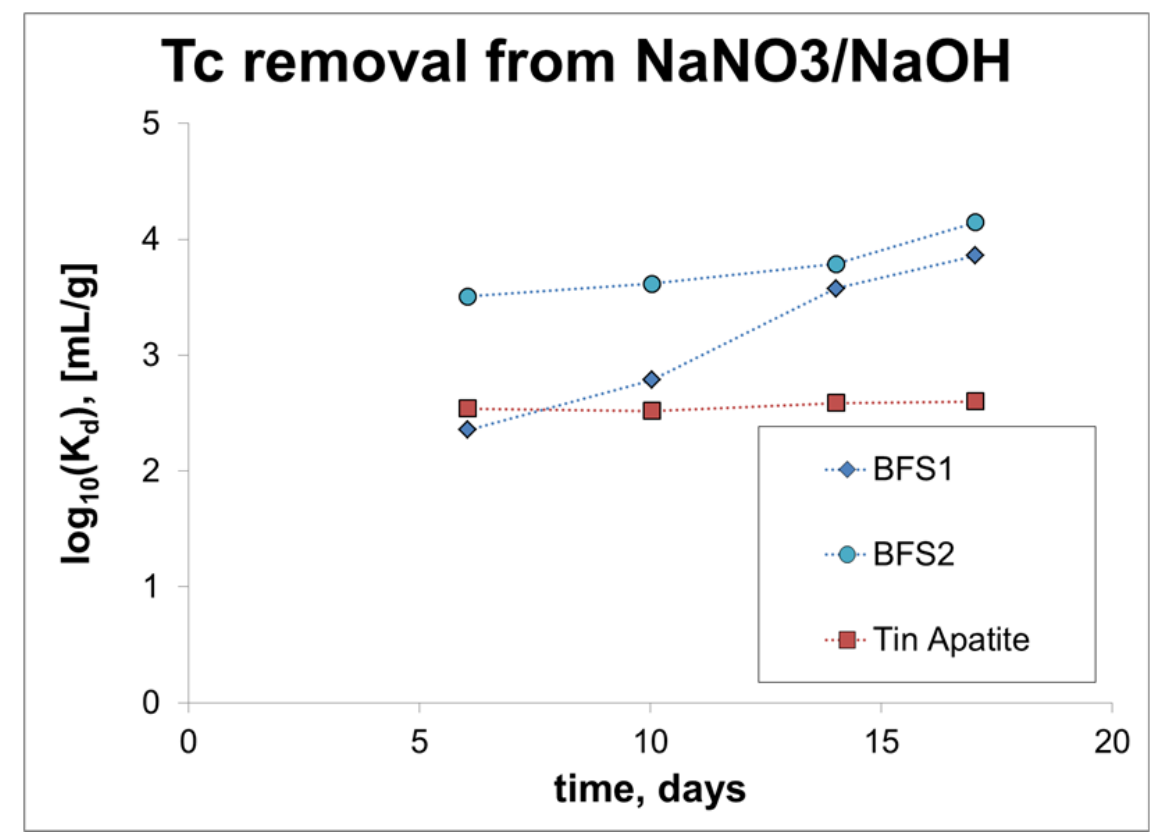

Figure 3.13. $\log \mathrm{K}_{\mathrm{d}}$ Values for Tc for the Three Getter Materials in a Mix of Sodium Nitrate and Sodium Hydroxide. The getter-mass-to-solution-volume ratio is 1:100. $\mathrm{K}_{\mathrm{d}}$ values have been corrected for volume lost during the periodic sampling.

By running these experiments, where $\mathrm{Cr}$ and $\mathrm{Tc}$ removal can be examined in a simplified system, it can be concluded that the getter materials have an affinity for both $\mathrm{Cr}$ and Tc. A third experiment ("Solution C" from Section 2.4.2) has been performed where both $\mathrm{Tc}$ and Cr have been placed into the solution at the same time. However, the results of those experiments were not available at the time of writing.

Once all of the data have been compiled, the effect of nitrate will also be examined. Nitrate is another solution species that may be directly competing for electrons with $\mathrm{Tc}$ as it is also able to be reduced from nitrate $\left(\mathrm{NO}_{3}{ }^{-}\right)$, where nitrogen is in the $7+$ oxidation state, to nitrite $\left(\mathrm{NO}_{2}{ }^{-}\right)$, where nitrogen is in the 5+ oxidation state, or to another nitrogen-containing species where nitrogen is present in an oxidation state lower than 7+. The effect of nitrate will be examined by running similar experiments in a solution composed of only $\mathrm{NaCl} / \mathrm{NaOH}$. If $\mathrm{Tc}$ and $\mathrm{Cr}$ removal by getters is again enhanced when the system does not contain nitrate, then it may be concluded that nitrate is also causing poor Tc removal by getters from the $7.8 \mathrm{M} \mathrm{Na}$ Ave simulant. 



\subsection{Conclusions}

Getter materials may serve as viable options to add to Cast Stone formulations to decrease Tc diffusivities from the waste form. In order to better understand the mechanisms by which Tc can be effectively removed from caustic LAW simulants and be retained by the getter materials, several batch sorption tests have been run. The solid getter material was separated from the contacting solution and examined using the solid-state characterization techniques of SEM and XAFS. Samples that were contacted with DI water and the 7.8 M Na Ave simulant were both examined with SEM but the results from the 7.8 M Na Ave simulant were inconclusive due to the high $\mathrm{Na}$ signal as well as the very small concentration of Tc sorbed on the getter surfaces. On the other hand, some meaningful results were obtained from the samples used in the DI water experiments. The EDS coupled with the images showed two types of behavior depending on if the material was a predominantly single-phase material or if it was a mixture of several phases. One example of the mixture of phases was the BFS samples. In these particular samples, the Tc was sorbed at certain locations on the BFS surfaces. For the BFS samples the Tc sorption may be at Oldhamite sites $(\mathrm{CaS})$, which have been identified to have a high reductive capacity by Um et al. (2013). An example of a seemingly homogeneous Tc absorption on a getter surface was observed for the single-phase getter Tin Apatite. The EDS for this material demonstrated that the Tc was distributed relatively evenly across the Tin Apatite sample surface.

The XAFS results were used to probe the oxidation state of the Tc sorbed onto the getter surface as well as the near-field environment of the Tc atoms. The oxidation state was determined with XANES. The results were fit with three standard spectra: $\mathrm{Tc}(\mathrm{IV}) \mathrm{O}_{4}{ }_{4}, \mathrm{Tc}(\mathrm{IV}) \mathrm{EDTA}$ that represents $\mathrm{Tc}(\mathrm{IV})$ coordinated by oxygen atoms in a distorted octahedral environment, and $\mathrm{Tc}_{2} \mathrm{O}_{7}$ that represents $\mathrm{Tc}(\mathrm{IV})$ coordinated by sulfide and disulfide ligands. The measurements were taken with two getter materials in contact with DI water (Tin Apatite and BFS 2) and two getter materials in contact with the $7.8 \mathrm{M}$ Na Ave simulant (Tin hydroxyapatite and KMS-2). Though Tc was present on all of the getter sample surfaces, the fits showed that Tc was primarily in the $\mathrm{TcO}_{4}{ }^{-}$form for the BFS 2 samples, in the $\mathrm{Tc}(\mathrm{IV})$ EDTA form for the Tin Apatite and Tin hydroxyapatite samples, and the majority was in the $\mathrm{Tc}_{2} \mathrm{O}_{7}$ form for KMS-2. Because the common understanding is that removal of Tc(VII) from solution involves reduction to Tc(IV), the results for BFS 2 were unexpected. It is unclear if this was a result of the slow reaction time of BFS (Um et al. 2011) or if the BFS 2 sample was reoxidized sometime during the XAFS measurement process. On the other hand, the Tin Apatite, which also showed the highest concentration of Tc for any of the samples, was shown to have $95 \%$ of Tc(IV)EDTA. For the two samples present in the $7.8 \mathrm{M}$ Na Ave simulant, the Tc was also present in the reduced form and coordinated by sulfide and disulfide ligands. For KMS-2, the result is expected because of the presence of sulfide in the starting material. However, for the Tin hydroxyapatite the result is somewhat unexpected because this getter does not contain sulfur. One possible explanation for the presence of this complex is from the sulfate source in the $7.8 \mathrm{M}$ Na Ave simulant that is present at a concentration of $130 \mathrm{mM}$. There may be some interaction of the $\mathrm{TcO}_{4}{ }^{-}$and sulfate in solution where the Tc and some of the sulfate is reduced by the Tin hydroxyapatite and both reduced species sorb on the Tin hydroxyapatite getter surface. It should be mentioned that this may not be the only mechanism responsible for Tc removal onto the Tin hydroxyapatite, as the XANES data shows both the $\mathrm{TcO}_{4}{ }^{-}$and $\mathrm{Tc}(\mathrm{IV}) \mathrm{EDTA}$ at $21 \%$ and $13 \%$, respectively.

Reliable EXAFS spectra were also obtained for Tin Apatite and KMS-2. No EXAFS data were available for BFS 2 because the sample did not contain a sufficient amount of Tc. The Tin Apatite data are consistent with the presence of $\mathrm{TcO}_{2} \bullet 2 \mathrm{H}_{2} \mathrm{O}$; also it does not match perfectly with the $\mathrm{TcO}_{2} \bullet 2 \mathrm{H}_{2} \mathrm{O}$ 
available in the literature (Lukens et al. 2002). There is no evidence of Tc interaction with the Tin Apatite elements $\mathrm{Sn}$ or $\mathrm{Ca}$ and the data suggest that the Tin Apatite getter acts as a simple reductant of $\mathrm{Tc}$ (VII) to form $\mathrm{TcO}_{2} \cdot 2 \mathrm{H}_{2} \mathrm{O}$. The data from KMS-2 show that Tc is present on the surface as a different phase than the species on the Tin Apatite surface. This confirms the XANES data and again suggests that more than one mechanism may be available for Tc removal from solution.

Along with solid-state characterization from a set of samples obtained from batch sorption experiments run by Qafoku et al. (2014), further batch sorption tests have been run to investigate if the removal of Tc from solution can be enhanced by adding a larger mass of getter material and to investigate the competition between $\mathrm{Tc}$ and $\mathrm{Cr}$ as they can both be reduced by the getter material. The three $\mathrm{Tc}$ getters were BFS 1 (northwest source), BFS 2 (southeast source), and Tin Apatite. Results from set of experiments varying the getter-mass-to-solution-volume ratio in DI water show that the addition of more getter mass improves both the overall removal of Tc as well as removing the Tc quicker from the solution. However, for the case where the $7.8 \mathrm{M} \mathrm{Na}$ Ave simulant was used, increasing the getter mass did not seem to enhance the removal of Tc for any of the getters.

The data presented in this report also show that $\mathrm{Tc}$ and $\mathrm{Cr}$ compete in the reduction process for the three getters tested (BFS 1, BFS 2, and Tin Apatite). When experiments investigating Tc removal in the absence of $\mathrm{Cr}$ from a 7.8 M Na Ave simulant were conducted, an enhancement of $1000 \times$ for the BFS materials and $100 \times$ for the Tin Apatite was observed compared to when the experiments were run using a 7.8 M Na Ave simulant with Cr. Therefore, $\mathrm{Cr}$ competes directly with Tc in terms of removal from solution by reduction. When the reduction potential values are available for all getters, calculations will be made to determine how much getter material is necessary to remove all available $\mathrm{Tc}$ and $\mathrm{Cr}$ from solution.

Further experiments are still necessary to understand the mechanism through which Tc can be effectively removed from solution, to find the optimum getter mass to achieve this, and to eventually incorporate this into the Cast Stone making process. 


\subsection{References}

Certa PJ, PA Empey, and MN Wells. 2011. River Protection Project System Plan. ORP-11242, Washington River Protection Solutions, LLC, Richland, WA.

DOE. 2012. Final Tank Closure and Waste Management Environmental Impact Statement for the Hanford Site, Richland, Washington (TC \& WM EIS). DOE/EIS-0391, U.S. Department of Energy, Office of River Protection, Richland, WA.

Duncan JB, GA Cooke, and LL Lockrem. 2008. Assessment of Technetium Leachability in Cement-Stablized Basin 43 Groundwater Brine. RPP-RPT-39195, Rev. 1, U.S. Department of Energy, Richland, WA.

Lukens WW, JJ Bucher, NM Edelstein, and DK Shuh. 2002. "Products of pertechnetate radiolysis in highly alkaline solution: Structure of $\mathrm{TcO}_{2} \bullet \mathrm{xH}_{2} \mathrm{O}$." Environmental Science \& Technology, 36, 1124-1129.

Lukens WW, JJ Bucher, DK Shuh, and NM Edelstein. 2005. "Evolution of Technetium Speciation in Reducing Grout." Environmental Science \& Technology, 39, 8064-8070.

Mann FM, KC Burgard, WR Root, RP Puigh, SH Finfrock, R Khaleel, DH Bacon, EJ Freeman, BP McGrail, SK Wurstner, and PE LaMont. 2001. Hanford Immobilization Low-Activity Tank Waste Performance Assessment: 2001 Version. DOE/ORP-2000-24, U.S. Department of Energy, Office of River Protection, Richland, WA.

Mann FM, RJ Puigh, SH Finfrock, R Khaleel, and MI Wood. 2003. Integrated Disposal Facility Risk Assessment. RPP-15834, Rev. 0, CH2M Hill Hanford Group, Inc., Richland, WA.

Mattigod SV, JH Westsik Jr, CW Chung, MJ Lindberg, and KE Parker. 2011. Waste Acceptance Testing of Secondary Waste Forms: Cast Stone, Ceramicrete and DuraLith. PNNL-20632, Pacific Northwest National Laboratory, Richland, WA.

Mertz JL, ZH Fard, CD Malliakas, MJ Manos, and MG Kanatzidis. 2013. "Selective Removal of Cs ${ }^{+}$, $\mathrm{Sr}^{2+}$, and $\mathrm{Ni}^{2+}$ by $\mathrm{K}_{2 \mathrm{x}} \mathrm{Mg}_{\mathrm{x}} \mathrm{Sn}_{3-\mathrm{x}} \mathrm{S}_{6}(\mathrm{x}=0.5-1)(\mathrm{KMS}-2)$ Relevant to Nuclear Waste Remediation."

Chemistry of Materials, 25, 2116-2127.

Pierce EM, DH Bacon, S Kerisit, CF Windisch, KJ Cantrell, MM Valenta, SD Burton, RJ Serne, and SV Mattigod. 2010a. Integrated Disposal Facility FY2010 Glass Testing Summary Report.

PNNL-19736, Pacific Northwest National Laboratory, Richland, WA.

Pierce EM, SV Mattigod, JH Westsik Jr, RJ Serne, JP Icenhower, RD Scheele, W Um, and NP Qafoku. 2010b. Review of Potential Candidate Stabilization Technologies for Liquid and Solid Secondary Waste Streams. PNNL-19122, Pacific Northwest National Laboratory, Richland, WA.

Qafoku NP, JJ Neeway, AR Lawter, TG Levitskaia, RJ Serne, JH Westsik Jr, and MM Valenta Snyder. 2014. Technetium and Iodine Getters to Improve Cast Stone Performance. PNNL-23282, Pacific Northwest National Laboratory, Richland, WA.

Ravel B and M Newville. 2005. "ATHENA and ARTEMIS: Interactive graphical data analysis using IFEFFIT." Physica Scripta, T115, 1007-1010. 
Serne RJ and JH Westsik Jr. 2011. Data Package for Secondary Waste Form Down-Selection - Cast Stone. PNNL-20706, Pacific Northwest National Laboratory, Richland, WA.

Sundaram SK, L Parker, MM Valenta, SG Pitman, J Chun, CW Chung, ML Kimura, CA Burns, W Um, and JH Westsik Jr. 2011. Secondary Waste Form Development and Optimization - Cast Stone.

PNNL-20159, Rev. 1, Pacific Northwest National Laboratory, Richland, WA.

Webb SM. 2005. "SIXpack: a graphical user interface for XAS analysis using IFEFFIT." Physica Scripta, T115, 1011-1014.

Westsik Jr, JH, GF Piepel, MJ Lindberg, PG Heasler, TM Mercier, RL Russell, AD Cozzi, WE Daniel, RE Eibling, EK Hansen, MR Reigal, and DJ Swanberg. 2013. Supplemental Immobilization of Hanford Low-Activity Waste: Cast Stone Screening Tests. PNNL-22747, SRNL-STI-2013-00465, Rev. 0, Pacific Northwest National Laboratory, Richland, WA and Savannah River National Laboratory, Aiken, SC. 


\section{Appendix A}

\section{Effluent Concentrations Calculated $K_{d}$ Values, and $p H$}



Table A.1. DI Water Samples for Varying Ratio Experiments

\begin{tabular}{|c|c|c|c|c|c|c|}
\hline Sample ID & $\begin{array}{c}\text { Sample } \\
\text { Time } \\
\text { (days) }\end{array}$ & $\begin{array}{c}\text { Solution } \\
\text { Volume } \\
(\mathrm{mL})\end{array}$ & $\begin{array}{c}{[T c], A} \\
(\mu \mathrm{g} / \mathrm{L})\end{array}$ & $\begin{array}{c}{[T c], B} \\
(\mu g / L)\end{array}$ & $\begin{array}{c}\text { Log(avg } \\
\text { Kd), } \\
{[\mathrm{mL} / \mathrm{g}]}\end{array}$ & $\begin{array}{c}\text { Log } \\
\text { stdev(avg } \\
\text { Kd) } \\
\end{array}$ \\
\hline BFS 1-1:10-1 & 0.1 & 100.0 & 29200 & 30900 & 0.95 & -0.12 \\
\hline BFS 1-1:10-2 & 1.0 & 98.0 & 797 & 4210 & 2.60 & 2.60 \\
\hline BFS 1-1:10-3 & 3.1 & 96.0 & 0.268 & 1.16 & 6.11 & 6.06 \\
\hline BFS 1-1:10-4 & 6.1 & 94.0 & 0.205 & 0.285 & 6.35 & 5.71 \\
\hline BFS 1-1:10-5 & 10.0 & 92.0 & 0.042 & 0.574 & 6.83 & 6.92 \\
\hline BFS 1-1:10-6 & 14.0 & 90.0 & 0.041 & 0.169 & 6.88 & 6.82 \\
\hline BFS 1-1:10-7 & 17.0 & 88.0 & 0.041 & 0.041 & 7.09 & 3.94 \\
\hline BFS 1-1:20-1 & 0.1 & 100.0 & 34800 & 37000 & 1.07 & 0.14 \\
\hline BFS 1-1:20-2 & 1.0 & 98.0 & 13900 & 18100 & 1.70 & 1.11 \\
\hline BFS 1-1:20-3 & 3.1 & 96.0 & 1090 & 4810 & 2.79 & 2.75 \\
\hline BFS 1-1:20-4 & 6.1 & 94.0 & 38.9 & 99.2 & 4.28 & 4.07 \\
\hline BFS 1-1:20-5 & 10.0 & 92.0 & 0.041 & 0.205 & 7.19 & 7.16 \\
\hline BFS 1-1:20-6 & 14.0 & 90.0 & 0.041 & 0.541 & 7.12 & 7.21 \\
\hline BFS 1-1:20-7 & 17.0 & 88.0 & 0.041 & 0.197 & 7.17 & 7.14 \\
\hline BFS 2-1:10-1 & 0.1 & 100.0 & 53300 & 51600 & -0.08 & -0.60 \\
\hline BFS 2-1:10-2 & 1.0 & 98.0 & 45800 & 41400 & 0.43 & -0.05 \\
\hline BFS 2-1:10-3 & 3.1 & 96.0 & 4220 & 15000 & 1.88 & 1.83 \\
\hline BFS 2-1:10-4 & 6.1 & 94.0 & 0.139 & 0.948 & 6.34 & 6.36 \\
\hline BFS 2-1:10-5 & 10.0 & 92.0 & 0.11 & 0.14 & 6.63 & 5.86 \\
\hline BFS 2-1:10-6 & 14.0 & 90.0 & 0.041 & 0.0916 & 6.95 & 6.68 \\
\hline BFS 2-1:10-7 & 17.0 & 88.0 & 0.041 & 0.041 & 7.09 & 3.94 \\
\hline BFS 2-1:20-1 & 0.1 & 100.0 & 57000 & 49900 & 0.44 & $\mathrm{NA}$ \\
\hline BFS 2-1:20-2 & 1.0 & 98.0 & 53000 & 50600 & 0.13 & -0.16 \\
\hline BFS 2-1:20-3 & 3.1 & 96.0 & 35400 & 40900 & 1.01 & 0.48 \\
\hline BFS 2-1:20-4 & 6.1 & 94.0 & 3840 & 5180 & 2.35 & 1.71 \\
\hline BFS 2-1:20-5 & 10.0 & 92.0 & 0.32 & 0.425 & 6.46 & 5.76 \\
\hline BFS 2-1:20-6 & 14.0 & 90.0 & 0.0805 & 0.13 & 7.00 & 6.53 \\
\hline BFS 2-1:20-7 & 17.0 & 88.0 & 0.041 & 0.052 & 7.34 & 6.57 \\
\hline
\end{tabular}

Note:

Values in italics are the estimated limit of quantification. 
Table A.1. (cont.)

\begin{tabular}{|c|c|c|c|c|c|c|}
\hline Sample ID & $\begin{array}{c}\text { Sample } \\
\text { Time } \\
\text { (days) }\end{array}$ & $\begin{array}{c}\text { Solution } \\
\text { Volume } \\
(\mathrm{mL})\end{array}$ & $\begin{array}{c}\text { [Tc], A } \\
(\mu \mathrm{g} / \mathrm{L})\end{array}$ & $\begin{array}{c}{[T c], B} \\
(\mu \mathrm{g} / \mathrm{L})\end{array}$ & $\begin{array}{c}\text { Log(avg } \\
\text { Kd), } \\
{[\mathrm{mL} / \mathrm{g}]}\end{array}$ & $\begin{array}{c}\text { Log } \\
\text { stdev(avg } \\
\text { Kd) }\end{array}$ \\
\hline Tin Apatite-1:10-1 & 0.1 & 100.0 & 2.86 & 0.551 & 5.84 & 5.82 \\
\hline Tin Apatite-1:10-2 & 1.0 & 98.0 & 0.205 & 0.205 & 6.47 & 3.32 \\
\hline Tin Apatite-1:10-3 & 3.1 & 96.0 & 0.205 & 0.205 & 6.48 & 3.33 \\
\hline Tin Apatite-1:10-4 & 6.1 & 94.0 & 0.205 & 0.205 & 6.46 & 3.31 \\
\hline Tin Apatite-1:10-5 & 10.0 & 92.0 & 0.041 & NA & 7.15 & NA \\
\hline Tin Apatite-1:10-6 & 14.0 & 90.0 & 0.041 & 0.041 & 7.14 & 5.39 \\
\hline Tin Apatite-1:10-7 & 17.0 & 88.0 & 0.041 & 0.041 & 7.14 & 5.40 \\
\hline Tin Apatite-1:20-1 & 0.1 & 100.0 & 5.33 & 2820 & 5.08 & 5.23 \\
\hline Tin Apatite-1:20-2 & 1.0 & 98.0 & 0.205 & 0.205 & 6.77 & 3.92 \\
\hline Tin Apatite-1:20-3 & 3.1 & 96.0 & 0.205 & 0.205 & 6.78 & 3.93 \\
\hline Tin Apatite-1:20-4 & 6.1 & 94.0 & 0.205 & 0.205 & 6.76 & 3.91 \\
\hline Tin Apatite-1:20-5 & 10.0 & 92.0 & 0.041 & 0.0618 & 7.38 & 6.83 \\
\hline Tin Apatite-1:20-6 & 14.0 & 90.0 & 0.041 & 0.0512 & 7.39 & 6.59 \\
\hline Tin Apatite-1:20-7 & 17.0 & 88.0 & 0.041 & 0.0513 & 7.39 & 6.59 \\
\hline Blank-1:10-1 & 0.1 & 100.0 & 59100 & 54500 & & \\
\hline Blank-1:10-2 & 1.0 & 98.0 & 55400 & 55300 & & \\
\hline Blank-1:10-3 & 3.1 & 96.0 & 58900 & 57200 & & \\
\hline Blank-1:10-4 & 6.1 & 94.0 & 57200 & 55400 & & \\
\hline Blank-1:10-5 & 10.0 & 92.0 & 56800 & 56800 & & \\
\hline Blank-1:10-6 & 14.0 & 90.0 & 55100 & 56000 & & \\
\hline Blank-1:10-7 & 17.0 & 88.0 & 58300 & 56000 & & \\
\hline
\end{tabular}

Notes:

These blank values were obtained in conjunction with the values given for BFS 1-1:10, BFS 1-1:20, BFS 21:10, BFS 2-1:20, and Tin Apatite-1:10, and Tin Apatite-1:20 for the experiments conducted in DI water.

Values in italics are the estimated limit of quantification. 
Table A.2. 7.8 M Na Ave Simulant for Varying Ratio Experiments

\begin{tabular}{|c|c|c|c|c|c|c|}
\hline Sample ID & $\begin{array}{c}\text { Sample } \\
\text { Time } \\
\text { (days) }\end{array}$ & $\begin{array}{c}\text { Solution } \\
\text { Volume } \\
\text { (mL) }\end{array}$ & $\begin{array}{c}\text { [Tc], A } \\
(\mu \mathrm{g} / \mathrm{L})\end{array}$ & $\begin{array}{c}{[\mathrm{Tc}], \mathrm{B}} \\
(\mu \mathrm{g} / \mathrm{L})\end{array}$ & $\begin{array}{c}\text { Log(avg } \\
\text { Kd), } \\
{[\mathrm{mL} / \mathrm{g}]}\end{array}$ & $\begin{array}{c}\text { Log } \\
\text { stdev(avg } \\
\text { Kd) }\end{array}$ \\
\hline BFS 1-1:10-1 & 0.1 & 100.0 & 58800 & 60500 & 0 & NA \\
\hline BFS 1-1:10-2 & 1.0 & 98.0 & 59400 & 51800 & -0.17 & NA \\
\hline BFS 1-1:10-3 & 3.1 & 96.0 & 54900 & 52000 & -0.07 & -0.39 \\
\hline BFS 1-1:10-4 & 6.1 & 94.0 & 51000 & 49200 & 0.07 & -0.57 \\
\hline BFS 1-1:10-5 & 10.0 & 92.0 & 51400 & 52700 & -0.07 & -0.75 \\
\hline BFS 1-1:10-6 & 14.0 & 90.0 & 51700 & 53200 & -0.27 & -0.71 \\
\hline BFS 1-1:10-7 & 17.0 & 88.0 & 53700 & 49000 & 0.01 & -0.19 \\
\hline BFS 1-1:20-1 & 0.1 & 100.0 & 58800 & 53900 & 0.04 & NA \\
\hline BFS 1-1:20-2 & 1.0 & 98.0 & 55400 & 57700 & 0 & NA \\
\hline BFS 1-1:20-3 & 3.1 & 96.0 & 54500 & 55900 & 0.00 & -0.44 \\
\hline BFS 1-1:20-4 & 6.1 & 94.0 & 49200 & 54200 & 0.24 & 0.15 \\
\hline BFS 1-1:20-5 & 10.0 & 92.0 & 51900 & 49300 & 0.36 & -0.12 \\
\hline BFS 1-1:20-6 & 14.0 & 90.0 & 54600 & 49300 & 0.12 & 0.15 \\
\hline BFS 1-1:20-7 & 17.0 & 88.0 & 52800 & 50400 & 0.28 & -0.19 \\
\hline BFS 2-1:10-1 & 0.1 & 100.0 & 58200 & 58300 & 0 & NA \\
\hline BFS 2-1:10-2 & 1.0 & 98.0 & 60200 & 52000 & -0.20 & NA \\
\hline BFS 2-1:10-3 & 3.1 & 96.0 & 55300 & 54200 & -0.24 & -0.84 \\
\hline BFS 2-1:10-4 & 6.1 & 94.0 & 49100 & 52500 & 0.01 & -0.30 \\
\hline BFS 2-1:10-5 & 10.0 & 92.0 & 38200 & 38000 & 0.66 & -1.32 \\
\hline BFS 2-1:10-6 & 14.0 & 90.0 & 36600 & 36000 & 0.68 & -0.80 \\
\hline BFS 2-1:10-7 & 17.0 & 88.0 & 33100 & 33400 & 0.80 & -0.99 \\
\hline BFS 2-1:20-1 & 0.1 & 100.0 & 65200 & 50500 & 0.40 & NA \\
\hline BFS 2-1:20-2 & 1.0 & 98.0 & 54000 & 56400 & -0.31 & NA \\
\hline BFS 2-1:20-3 & 3.1 & 96.0 & 52000 & 55500 & 0.19 & -0.02 \\
\hline BFS 2-1:20-4 & 6.1 & 94.0 & 53200 & 51400 & 0.16 & -0.31 \\
\hline BFS 2-1:20-5 & 10.0 & 92.0 & 43700 & 48400 & 0.64 & 0.22 \\
\hline BFS 2-1:20-6 & 14.0 & 90.0 & 45700 & 43200 & 0.65 & -0.05 \\
\hline BFS 2-1:20-7 & 17.0 & 88.0 & 44000 & 45900 & 0.68 & -0.17 \\
\hline
\end{tabular}


Table A.2. (cont.)

\begin{tabular}{|l|r|r|r|r|r|r|}
\hline Sample ID & $\begin{array}{c}\text { Sample } \\
\text { Time } \\
\text { (days) }\end{array}$ & $\begin{array}{c}\text { Solution } \\
\text { Volume } \\
\mathbf{( m L )}\end{array}$ & $\begin{array}{c}\text { [Tc], A } \\
\mathbf{( \mu g / L )}\end{array}$ & $\begin{array}{r}\text { [Tc], } \mathbf{B} \\
\mathbf{( \mu g / L )}\end{array}$ & $\begin{array}{c}\text { Log(avg } \\
\text { Kd), } \\
\text { [mL/g] }\end{array}$ & $\begin{array}{r}\text { Log } \\
\text { stdev(avg } \\
\text { Kd) }\end{array}$ \\
\hline Tin Apatite-1:10-1 & 0.1 & 100.0 & 54600 & 55800 & -0.49 & -0.75 \\
Tin Apatite-1:10-2 & 1.0 & 98.0 & 51300 & 47800 & 0.11 & -0.21 \\
Tin Apatite-1:10-3 & 3.1 & 96.0 & 46800 & 41900 & 0.53 & 0.04 \\
Tin Apatite-1:10-4 & 6.1 & 94.0 & 48200 & 46400 & 0.30 & -0.47 \\
Tin Apatite-1:10-5 & 10.0 & 92.0 & 51100 & 43700 & 0.33 & 0.14 \\
Tin Apatite-1:10-6 & 14.0 & 90.0 & 51800 & 45400 & 0.17 & 0.03 \\
Tin Apatite-1:10-7 & 17.0 & 88.0 & 53900 & 45200 & 0.20 & 0.15 \\
\hline Tin Apatite-1:20-1 & 0.1 & 100.0 & 55200 & 58800 & -0.19 & NA \\
Tin Apatite-1:20-2 & 1.0 & 98.0 & 50000 & 53600 & 0.19 & 0.06 \\
Tin Apatite-1:20-3 & 3.1 & 96.0 & 56900 & 48300 & 0.38 & 0.44 \\
Tin Apatite-1:20-4 & 6.1 & 94.0 & 53400 & 54400 & -0.03 & -0.54 \\
Tin Apatite-1:20-5 & 10.0 & 92.0 & 53100 & 52500 & 0.19 & -0.75 \\
Tin Apatite-1:20-6 & 14.0 & 90.0 & 51800 & 53200 & 0.07 & -0.39 \\
Tin Apatite-1:20-7 & 17.0 & 88.0 & 51600 & 53000 & 0.26 & -0.39 \\
\hline Blank-1:10-1 & 0.1 & 100.0 & 59100 & 54500 & & \\
Blank-1:10-2 & 1.0 & 98.0 & 55400 & 55300 & & \\
Blank-1:10-3 & 3.1 & 96.0 & 58900 & 57200 & & \\
Blank-1:10-4 & 6.1 & 94.0 & 57200 & 55400 & & \\
Blank-1:10-5 & 10.0 & 92.0 & 56800 & 56800 & & \\
Blank-1:10-6 & 14.0 & 90.0 & 55100 & 56000 & & \\
Blank-1:10-7 & 17.0 & 88.0 & 58300 & 56000 & & \\
\hline Note: & & & & &
\end{tabular}

Note:

These blank values were obtained in conjunction with the values given for BFS 1-1:10, BFS 1-1:20, BFS 21:10, BFS 2-1:20, and Tin Apatite-1:10, and Tin Apatite-1:20 for the experiments conducted in the $7.8 \mathrm{M} \mathrm{Na}$ Ave simulant. 
Table A.3. Samples for Batch Sorption of Tc in the Absence of $\mathrm{Cr}$

\begin{tabular}{|c|c|c|c|c|c|c|}
\hline Sample ID & $\begin{array}{c}\text { Sample } \\
\text { Time } \\
\text { (days) }\end{array}$ & $\begin{array}{c}\text { Solution } \\
\text { volume } \\
(\mathrm{mL})\end{array}$ & $\begin{array}{c}\text { [Tc], A } \\
(\mu \mathrm{g} / \mathrm{L})\end{array}$ & $\begin{array}{c}{[T c], B} \\
(\mu \mathrm{g} / \mathrm{L})\end{array}$ & $\begin{array}{c}\text { Log(avg } \\
\text { Kd), } \\
{[\mathrm{mL} / \mathrm{g}]}\end{array}$ & $\begin{array}{c}\text { Log } \\
\text { stdev(avg } \\
\text { Kd) }\end{array}$ \\
\hline BFS 1-C1-7.8M-No Cr-1 & 0.1 & 100.0 & 5820 & 5020 & 1.12 & NA \\
\hline BFS 1-C1-7.8M-No Cr-2 & 1.0 & 98.0 & 4350 & 3930 & 1.60 & 1.00 \\
\hline BFS 1-C1-7.8M-No Cr-3 & 2.1 & 96.0 & 2690 & 2990 & 1.95 & 1.14 \\
\hline BFS 1-C1-7.8M-No Cr-4 & 6.0 & 94.0 & 769 & 696 & 2.82 & 1.72 \\
\hline BFS 1-C1-7.8M-No Cr-5 & 8.0 & 92.0 & 657 & 520 & 2.89 & 2.16 \\
\hline BFS 1-C1-7.8M-No Cr-6 & 12.1 & 90.0 & 588 & 592 & 2.89 & 0.62 \\
\hline BFS 1-C1-7.8M-No Cr-7 & 15.0 & 88.0 & 560 & 385 & 2.99 & 2.45 \\
\hline BFS 1-C1-7.8M-No Cr-8 & 70.0 & 86.0 & 610 & 461 & 2.85 & 2.20 \\
\hline BFS 1-C2-7.8M-No Cr-1 & 0.1 & 100.0 & 27700 & 28200 & 0 & $\overline{\mathrm{NA}}$ \\
\hline BFS 1-C2-7.8M-No Cr-2 & 1.0 & 98.0 & 21800 & 23200 & 1.37 & 0.73 \\
\hline BFS 1-C2-7.8M-No Cr-3 & 2.1 & 96.0 & 19100 & 20900 & 1.57 & 0.93 \\
\hline BFS 1-C2-7.8M-No Cr-4 & 6.0 & 94.0 & 11400 & 11800 & 2.13 & 0.75 \\
\hline BFS 1-C2-7.8M-No Cr-5 & 8.0 & 92.0 & 7170 & 8100 & 2.39 & 1.46 \\
\hline BFS 1-C2-7.8M-No Cr-6 & 12.1 & 90.0 & 3740 & 4550 & 2.71 & 1.92 \\
\hline BFS 1-C2-7.8M-No Cr-7 & 15.0 & 88.0 & 1890 & 2190 & 3.02 & 2.07 \\
\hline BFS 1-C2-7.8M-No Cr-8 & 71.0 & 86.0 & 779 & 726 & 3.45 & 2.16 \\
\hline BFS 1-C3-7.8M-No Cr-1 & 0.1 & 100.0 & 51000 & 55500 & 0.96 & 0.82 \\
\hline BFS 1-C3-7.8M-No Cr-2 & 0.8 & 98.0 & 49800 & 50700 & 0.84 & 0.15 \\
\hline BFS 1-C3-7.8M-No Cr-3 & 1.9 & 96.0 & 47400 & 46900 & 1.36 & -0.13 \\
\hline BFS 1-C3-7.8M-No Cr-4 & 5.8 & 94.0 & 37100 & 37300 & 1.68 & -0.06 \\
\hline BFS 1-C3-7.8M-No Cr-5 & 7.8 & 92.0 & 33300 & 30500 & 1.85 & 0.99 \\
\hline BFS 1-C3-7.8M-No Cr-6 & 11.9 & 90.0 & 31100 & 27000 & 1.96 & 1.24 \\
\hline BFS 1-C3-7.8M-No Cr-7 & 14.8 & 88.0 & 26300 & 24400 & 2.00 & 0.97 \\
\hline BFS 1-C3-7.8M-No Cr-8 & 70.8 & 86.0 & 9260 & 10000 & 2.55 & 1.42 \\
\hline BFS 1-C3-7.8M-Yes Cr-1 & 0.1 & 100.0 & 57300 & 53400 & 0.76 & 0.73 \\
\hline BFS 1-C3-7.8M-Yes Cr-2 & 0.8 & 98.0 & 48500 & 55900 & 1.07 & 1.04 \\
\hline BFS 1-C3-7.8M-Yes Cr-3 & 1.9 & 96.0 & 51000 & 59300 & 1.00 & NA \\
\hline BFS 1-C3-7.8M-Yes Cr-4 & 5.8 & 94.0 & 51200 & 52000 & 1.10 & 0.04 \\
\hline BFS 1-C3-7.8M-Yes Cr-5 & 7.8 & 92.0 & 56200 & 50000 & 1.02 & 0.94 \\
\hline BFS 1-C3-7.8M-Yes Cr-6 & 11.9 & 90.0 & 53300 & 50400 & 0.83 & 0.59 \\
\hline BFS 1-C3-7.8M-Yes Cr-7 & 14.8 & 88.0 & 54000 & 50700 & 0.42 & NA \\
\hline BFS 1-C3-7.8M-Yes Cr-8 & 70.8 & 86.0 & 47400 & 47300 & 0.53 & -0.80 \\
\hline
\end{tabular}


Table A.3. (cont.)

\begin{tabular}{|c|c|c|c|c|c|c|}
\hline Sample ID & $\begin{array}{c}\text { Sample } \\
\text { Time } \\
\text { (days) }\end{array}$ & $\begin{array}{c}\text { Solution } \\
\text { Volume } \\
(\mathrm{mL})\end{array}$ & $\begin{array}{c}\text { [Tc], A } \\
(\mu \mathrm{g} / \mathrm{L})\end{array}$ & $\begin{array}{c}{[T c], B} \\
(\mu \mathrm{g} / \mathrm{L})\end{array}$ & $\begin{array}{c}\text { Log(avg } \\
\text { Kd), } \\
{[\mathrm{mL} / \mathrm{g}]}\end{array}$ & $\begin{array}{c}\text { Log } \\
\text { stdev(avg } \\
\text { Kd) }\end{array}$ \\
\hline BFS 2-C1-7.8M-No Cr-1 & 0.1 & 100.0 & 5660 & 5660 & 0.81 & 0.95 \\
\hline BFS 2-C1-7.8M-No Cr-2 & 1.0 & 98.0 & 4780 & 4780 & 1.44 & 1.00 \\
\hline BFS 2-C1-7.8M-No Cr-3 & 2.1 & 96.0 & 554 & 554 & 2.91 & 1.74 \\
\hline BFS 2-C1-7.8M-No Cr-4 & 6.0 & 94.0 & 306 & 306 & 3.23 & 1.86 \\
\hline BFS 2-C1-7.8M-No Cr-5 & 8.0 & 92.0 & 311 & 311 & 3.26 & 2.63 \\
\hline BFS 2-C1-7.8M-No Cr-6 & 12.1 & 90.0 & 282 & 282 & 3.28 & 2.43 \\
\hline BFS 2-C1-7.8M-No Cr-7 & 15.0 & 88.0 & 239 & 239 & 3.32 & 2.39 \\
\hline BFS 2-C1-7.8M-No Cr-8 & 71.0 & 86.0 & 235 & 235 & 3.24 & 1.96 \\
\hline BFS 2-C2-7.8M-No Cr-1 & 0.1 & 100.0 & 25500 & 25900 & 0.77 & 0.07 \\
\hline BFS 2-C2-7.8M-No Cr-2 & 1.0 & 98.0 & 21800 & 24600 & 1.31 & 1.00 \\
\hline BFS 2-C2-7.8M-No Cr-3 & 2.1 & 96.0 & 17100 & 17600 & 1.75 & 0.49 \\
\hline BFS 2-C2-7.8M-No Cr-4 & 6.0 & 94.0 & 1420 & 1220 & 3.29 & 2.34 \\
\hline BFS 2-C2-7.8M-No Cr-5 & 8.0 & 92.0 & 845 & 667 & 3.17 & 3.32 \\
\hline BFS2-C2-7.8M-No Cr-6 & 12.1 & 90.0 & 640 & 593 & 3.60 & 2.45 \\
\hline BFS2-C2-7.8M-No Cr-7 & 15.0 & 88.0 & 575 & 528 & 3.62 & 2.51 \\
\hline BFS2-C2-7.8M-No Cr-8 & 71.0 & 86.0 & 478 & 490 & 3.65 & 0.86 \\
\hline BFS2-C3-7.8M-No Cr-1 & 0.1 & 100.0 & 55000 & 48400 & 1.10 & 1.01 \\
\hline BFS 2-C3-7.8M-No Cr-2 & 0.8 & 98.0 & 52300 & 55400 & 0.43 & NA \\
\hline BFS 2-C3-7.8M-No Cr-3 & 1.9 & 96.0 & 39200 & 44000 & 1.59 & 1.03 \\
\hline BFS 2-C3-7.8M-No Cr-4 & 5.8 & 94.0 & 22700 & 26100 & 2.09 & 1.31 \\
\hline BFS 2-C3-7.8M-No Cr-5 & 7.8 & 92.0 & 13800 & 16200 & 2.41 & 1.57 \\
\hline BFS 2-C3-7.8M-No Cr-6 & 11.9 & 90.0 & 8730 & 11500 & 2.64 & 2.00 \\
\hline BFS 2-C3-7.8M-No Cr-7 & 14.8 & 88.0 & 4620 & 7320 & 2.87 & 2.42 \\
\hline BFS 2-C3-7.8M-No Cr-8 & 70.8 & 86.0 & 553 & 599 & 3.86 & 2.56 \\
\hline BFS 2-C3-7.8M-Yes Cr-1 & 0.1 & 100.0 & 54800 & 52400 & 0.96 & 0.54 \\
\hline BFS 2-C3-7.8M-Yes Cr-2 & 0.8 & 98.0 & 53800 & 57800 & 0.62 & 0.72 \\
\hline BFS 2-C3-7.8M-Yes Cr-3 & 1.9 & 96.0 & 52300 & 53100 & 0.81 & 0.04 \\
\hline BFS 2-C3-7.8M-Yes Cr-4 & 5.8 & 94.0 & 53000 & 53300 & 0.97 & -0.38 \\
\hline BFS 2-C3-7.8M-Yes Cr-5 & 7.8 & 92.0 & 53700 & 55700 & 0.84 & 0.41 \\
\hline BFS 2-C3-7.8M-Yes Cr-6 & 11.9 & 90.0 & 49400 & 52300 & 0.93 & 0.60 \\
\hline BFS 2-C3-7.8M-Yes Cr-7 & 14.8 & 88.0 & 46600 & 48000 & 0.96 & 0.31 \\
\hline BFS 2-C3-7.8M-Yes Cr-8 & 70.8 & 86.0 & 45700 & 49500 & 0.82 & NA \\
\hline
\end{tabular}


Table A.3. (cont.)

\begin{tabular}{|c|c|c|c|c|c|c|}
\hline Sample ID & $\begin{array}{c}\text { Sample } \\
\text { Time } \\
\text { (days) }\end{array}$ & $\begin{array}{c}\text { Solution } \\
\text { Volume } \\
\text { (mL) }\end{array}$ & $\begin{array}{c}\text { [Tc], A } \\
(\mu \mathrm{g} / \mathrm{L})\end{array}$ & $\begin{array}{c}{[\mathrm{Tc}], \mathrm{B}} \\
(\mu \mathrm{g} / \mathrm{L})\end{array}$ & $\begin{array}{c}\text { Log(avg } \\
\text { Kd), } \\
\text { [mL/g] }\end{array}$ & $\begin{array}{c}\text { Log } \\
\text { stdev(avg } \\
\text { Kd) }\end{array}$ \\
\hline Tin Ap-C1-7.8M-No Cr-1 & 0.1 & 100.0 & 4280 & 3800 & 1.66 & 1.12 \\
\hline Tin Ap-C1-7.8M-No Cr-2 & 1.0 & 98.0 & 3690 & 3320 & 1.86 & 1.13 \\
\hline Tin Ap-C1-7.8M-No Cr-3 & 2.1 & 96.0 & 2850 & 3080 & 1.96 & 1.04 \\
\hline Tin Ap-C1-7.8M-No Cr-4 & 6.0 & 94.0 & 3090 & 2680 & 2.03 & 1.33 \\
\hline Tin Ap-C1-7.8M-No Cr-5 & 8.0 & 92.0 & 3190 & 1560 & 2.22 & 2.12 \\
\hline Tin Ap-C1-7.8M-No Cr-6 & 12.1 & 90.0 & 2360 & 2590 & 2.12 & 1.18 \\
\hline Tin Ap-C1-7.8M-No Cr-7 & 15.0 & 88.0 & 2840 & 2590 & 2.01 & 1.12 \\
\hline Tin Ap-C1-7.8M-No Cr-8 & 71.0 & 86.0 & 2050 & 2160 & 2.10 & 0.91 \\
\hline Tin Ap-C2-7.8M-No Cr-1 & 0.1 & 100.0 & 21700 & 11100 & 1.98 & 1.98 \\
\hline Tin Ap-C2-7.8M-No Cr-2 & 1.0 & 98.0 & 10200 & 16700 & 2.12 & 1.92 \\
\hline Tin Ap-C2-7.8M-No Cr-3 & 2.1 & 96.0 & 11900 & 14600 & 2.07 & 1.51 \\
\hline Tin Ap-C2-7.8M-No Cr-4 & 6.0 & 94.0 & 11800 & 14900 & 2.08 & 1.57 \\
\hline Tin Ap-C2-7.8M-No Cr-5 & 8.0 & 92.0 & 13400 & 11900 & 2.09 & 1.28 \\
\hline Tin Ap-C2-7.8M-No Cr-6 & 12.1 & 90.0 & 11400 & 14200 & 2.07 & 1.53 \\
\hline Tin Ap-C2-7.8M-No Cr-7 & 15.0 & 88.0 & 9420 & 12800 & 2.14 & 1.71 \\
\hline Tin Ap-C2-7.8M-No Cr-8 & 71.0 & 86.0 & 8190 & 9470 & 2.26 & 1.46 \\
\hline Tin Ap-C3-7.8M-No Cr-1 & 0.1 & 100.0 & 22500 & 38600 & 2.06 & 1.93 \\
\hline Tin Ap-C3-7.8M-No Cr-2 & 0.8 & 98.0 & 27400 & 30900 & 1.97 & 1.24 \\
\hline Tin Ap-C3-7.8M-No Cr-3 & 1.9 & 96.0 & 22400 & 25500 & 2.19 & 1.38 \\
\hline Tin Ap-C3-7.8M-No Cr-4 & 5.8 & 94.0 & 18000 & 21900 & 2.28 & 1.61 \\
\hline Tin Ap-C3-7.8M-No Cr-5 & 7.8 & 92.0 & 17900 & 16600 & 2.36 & 1.25 \\
\hline Tin Ap-C3-7.8M-No Cr-6 & 11.9 & 90.0 & 14800 & 16500 & 2.43 & 1.46 \\
\hline Tin Ap-C3-7.8M-No Cr-7 & 14.8 & 88.0 & 13900 & 13800 & 2.45 & 0.29 \\
\hline Tin Ap-C3-7.8M-No Cr-8 & 70.8 & 86.0 & 11300 & 13100 & 2.46 & 1.60 \\
\hline Tin Ap-C3-7.8M-Yes Cr-1 & 0.1 & 100.0 & 56000 & 55400 & 0.73 & -0.05 \\
\hline Tin Ap-C3-7.8M-Yes Cr-2 & 0.8 & 98.0 & 54200 & 52100 & 1.01 & 0.53 \\
\hline Tin Ap-C3-7.8M-Yes Cr-3 & 1.9 & 96.0 & 39700 & 54700 & 1.38 & 1.47 \\
\hline Tin Ap-C3-7.8M-Yes Cr-4 & 5.8 & 94.0 & 53300 & 53500 & 1.00 & -0.52 \\
\hline Tin Ap-C3-7.8M-Yes Cr-5 & 7.8 & 92.0 & 51700 & 58800 & 0.85 & 1.00 \\
\hline Tin Ap-C3-7.8M-Yes Cr-6 & 11.9 & 90.0 & 53900 & 57200 & 0.50 & NA \\
\hline Tin Ap-C3-7.8M-Yes Cr-7 & 14.8 & 88.0 & 55100 & 56700 & 0 & NA \\
\hline Tin Ap-C3-7.8M-Yes Cr-8 & 70.8 & 86.0 & 48400 & 46300 & 0.58 & 0.50 \\
\hline
\end{tabular}


Table A.3. (cont.)

\begin{tabular}{|c|c|c|c|c|}
\hline Sample ID & $\begin{array}{c}\text { Sample } \\
\text { Time } \\
\text { (days) }\end{array}$ & $\begin{array}{c}\text { Solution } \\
\text { Volume } \\
\text { (mL) }\end{array}$ & $\begin{array}{c}\text { [Tc], A } \\
(\mu \mathrm{g} / \mathrm{L})\end{array}$ & $\begin{array}{c}{[T c], B} \\
(\mu \mathrm{g} / \mathrm{L})\end{array}$ \\
\hline BLK-C1-7.8M-No Cr-1 & 0.1 & 100.0 & 6180 & 5160 \\
\hline BLK-C1-7.8M-No Cr-2 & 1.0 & 98.0 & 5850 & 5730 \\
\hline BLK-C1-7.8M-No Cr-3 & 2.1 & 96.0 & 5320 & 5590 \\
\hline BLK-C1-7.8M-No Cr-4 & 6.0 & 94.0 & 5940 & 5610 \\
\hline BLK-C1-7.8M-No Cr-5 & 8.0 & 92.0 & 5790 & 5150 \\
\hline BLK-C1-7.8M-No Cr-6 & 12.1 & 90.0 & 5990 & 5350 \\
\hline BLK-C1-7.8M-No Cr-7 & 15.0 & 88.0 & 5350 & 5660 \\
\hline BLK-C1-7.8M-No Cr-8 & 71.0 & 86.0 & 4870 & 4830 \\
\hline BLK-C2-7.8M-No Cr-1 & 0.1 & 100.0 & 27200 & $-\cdots$ \\
\hline BLK-C2-7.8M-No Cr-2 & 1.0 & 98.0 & 27900 & -- \\
\hline BLK-C2-7.8M-No Cr-3 & 2.1 & 96.0 & 27600 & --- \\
\hline BLK-C2-7.8M-No Cr-4 & 6.0 & 94.0 & 28300 & -- \\
\hline BLK-C2-7.8M-No Cr-5 & 8.0 & 92.0 & 27700 & --- \\
\hline BLK-C2-7.8M-No Cr-6 & 12.1 & 90.0 & 27500 & -- \\
\hline BLK-C2-7.8M-No Cr-7 & 15.0 & 88.0 & 26100 & --- \\
\hline BLK-C2-7.8M-No Cr-8 & 71.0 & 86.0 & 25500 & -- \\
\hline BLK-C3-7.8M-No Cr-1 & 0.1 & 100.0 & 57900 & 57900 \\
\hline BLK-C3-7.8M-No Cr-2 & 0.8 & 98.0 & 52600 & 54900 \\
\hline BLK-C3-7.8M-No Cr-3 & 1.9 & 96.0 & 57100 & 59300 \\
\hline BLK-C3-7.8M-No Cr-4 & 5.8 & 94.0 & 51800 & 59600 \\
\hline BLK-C3-7.8M-No Cr-5 & 7.8 & 92.0 & 58100 & 53700 \\
\hline BLK-C3-7.8M-No Cr-6 & 11.9 & 90.0 & 55700 & 59800 \\
\hline BLK-C3-7.8M-No Cr-7 & 14.8 & 88.0 & 52900 & 53900 \\
\hline BLK-C3-7.8M-No Cr-8 & 70.8 & 86.0 & 48600 & 48200 \\
\hline BLK-C3-7.8M-Yes Cr-1 & 0.1 & 100.0 & 59100 & 57700 \\
\hline BLK-C3-7.8M-Yes Cr-2 & 0.8 & 98.0 & 56500 & 59700 \\
\hline BLK-C3-7.8M-Yes Cr-3 & 1.9 & 96.0 & 54600 & 57900 \\
\hline BLK-C3-7.8M-Yes Cr-4 & 5.8 & 94.0 & 58800 & 58100 \\
\hline BLK-C3-7.8M-Yes Cr-5 & 7.8 & 92.0 & 58600 & 59000 \\
\hline BLK-C3-7.8M-Yes Cr-6 & 11.9 & 90.0 & 55600 & 55600 \\
\hline BLK-C3-7.8M-Yes Cr-7 & 14.8 & 88.0 & 51500 & 52900 \\
\hline BLK-C3-7.8M-Yes Cr-8 & 70.8 & 86.0 & 49400 & 49000 \\
\hline
\end{tabular}


Table A.4. Samples for Batch Sorption of Cr in the Absence of Tc

\begin{tabular}{|c|c|c|c|c|c|c|}
\hline Sample ID & $\begin{array}{l}\text { Sample } \\
\text { Time } \\
\text { (days) }\end{array}$ & $\begin{array}{c}\text { Solution } \\
\text { Volume } \\
(\mathrm{mL})\end{array}$ & $\begin{array}{c}{[\mathrm{Cr}], \mathrm{A}} \\
(\mu \mathrm{g} / \mathrm{L})\end{array}$ & $\begin{array}{c}{[\mathrm{Cr}], \mathrm{B}} \\
(\mu \mathrm{g} / \mathrm{L})\end{array}$ & $\begin{array}{c}\text { Log(avg } \\
\text { Kd), } \\
{[\mathrm{mL} / \mathrm{g}]}\end{array}$ & $\begin{array}{c}\text { Log } \\
\text { stdev(avg } \\
\text { Kd) } \\
\end{array}$ \\
\hline BFS 1-No Tc-DI-1 & 1.0 & 100.0 & 15.4 & 12.1 & --- & --- \\
\hline BFS 1-No Tc-DI-2 & 1.9 & 98.0 & 12.6 & 13.4 & --- & --- \\
\hline BFS 1-No Tc-DI-3 & 3.9 & 96.0 & 12.8 & 14 & --- & --- \\
\hline BFS 1-No Tc-DI-4 & 6.9 & 94.0 & 15.8 & 15.7 & --- & --- \\
\hline BFS 1-No Tc-DI-5 & 10.9 & 92.0 & 17.2 & 15.7 & --- & --- \\
\hline BFS 1-No Tc-DI-6 & 14.9 & 90.0 & 14.6 & 13.8 & --- & --- \\
\hline BFS 1-No Tc-DI-7 & 17.9 & 88.0 & 14.8 & 16.8 & --- & --- \\
\hline BFS 1-No Tc-7.8M-1 & 1.0 & 100.0 & 1940000 & 1960000 & 0 & $\mathrm{NA}$ \\
\hline BFS 1-No Tc-7.8M-2 & 1.9 & 98.0 & 1960000 & 1940000 & 0 & NA \\
\hline BFS 1-No Tc-7.8M-3 & 3.9 & 96.0 & 1920000 & 1950000 & 0 & NA \\
\hline BFS 1-No Tc-7.8M-4 & 6.9 & 94.0 & 2110000 & 2040000 & 0.27 & NA \\
\hline BFS 1-No Tc-7.8M-5 & 10.9 & 92.0 & 2050000 & 2330000 & 0.73 & NA \\
\hline BFS 1-No Tc-7.8M-6 & 14.9 & 90.0 & 2080000 & 2080000 & -0.36 & -2.51 \\
\hline BFS 1-No Tc-7.8M-7 & 17.9 & 88.0 & 1990000 & 2160000 & 0.62 & NA \\
\hline BFS 2-No Tc-DI-1 & 1.0 & 100.0 & 9.58 & 9.58 & --- & --- \\
\hline BFS 2-No Tc-DI-2 & 1.9 & 98.0 & 9.58 & 9.58 & --- & --- \\
\hline BFS 2-No Tc-DI-3 & 3.9 & 96.0 & 9.58 & 9.58 & --- & --- \\
\hline BFS 2-No Tc-DI-4 & 6.9 & 94.0 & 10.4 & 10.4 & --- & --- \\
\hline BFS 2-No Tc-DI-5 & 10.9 & 92.0 & 10.4 & 10.4 & --- & --- \\
\hline BFS 2-No Tc-DI-6 & 14.9 & 90.0 & 10.4 & 10.4 & --- & --- \\
\hline BFS 2-No Tc-DI-7 & 17.9 & 88.0 & 10.4 & 10.4 & --- & --- \\
\hline BFS 2-No Tc-7.8M-1 & 1.0 & 100.0 & 1900000 & 1880000 & 0 & NA \\
\hline BFS 2-No Tc-7.8M-2 & 1.9 & 98.0 & 1930000 & 1900000 & 0 & NA \\
\hline BFS 2-No Tc-7.8M-3 & 3.9 & 96.0 & 1950000 & 1900000 & 0 & NA \\
\hline BFS 2-No Tc-7.8M-4 & 6.9 & 94.0 & 2170000 & 2060000 & 0 & NA \\
\hline BFS 2-No Tc-7.8M-5 & 10.9 & 92.0 & 2100000 & 2010000 & 0.87 & NA \\
\hline BFS 2-No Tc-7.8M-6 & 14.9 & 90.0 & 2180000 & 2110000 & 0 & NA \\
\hline BFS 2-No Tc-7.8M-7 & 17.9 & 88.0 & 2100000 & 2040000 & 0.29 & NA \\
\hline
\end{tabular}

Note:

Values in italics are the estimated limit of quantification. 
Table A.4. (cont.)

\begin{tabular}{|c|c|c|c|c|c|c|}
\hline Sample ID & $\begin{array}{l}\text { Sample } \\
\text { Time } \\
\text { (days) }\end{array}$ & $\begin{array}{c}\text { Solution } \\
\text { Volume } \\
(\mathrm{mL})\end{array}$ & $\begin{array}{c}\text { [Cr], A } \\
(\mu \mathrm{g} / \mathrm{L})\end{array}$ & $\begin{array}{c}{[\mathrm{Cr}], \mathrm{B}} \\
(\mu \mathrm{g} / \mathrm{L})\end{array}$ & $\begin{array}{c}\text { Log(avg } \\
\text { Kd), } \\
{[\mathrm{mL} / \mathrm{g}]}\end{array}$ & $\begin{array}{c}\text { Log } \\
\text { stdev(avg } \\
\text { Kd) }\end{array}$ \\
\hline Tin Ap-No Tc-DI-1 & 1.0 & 100.0 & 31.4 & 9.58 & --- & $\begin{array}{c}-- \\
-\end{array}$ \\
\hline Tin Ap-No Tc-DI-2 & 1.9 & 98.0 & 9.58 & 9.58 & --- & --- \\
\hline Tin Ap-No Tc-DI-3 & 3.9 & 96.0 & 24.8 & 9.58 & --- & --- \\
\hline Tin Ap-No Tc-DI-4 & 6.9 & 94.0 & 10.4 & 10.4 & --- & --- \\
\hline Tin Ap-No Tc-DI-5 & 10.9 & 92.0 & 10.4 & 10.4 & --- & --- \\
\hline Tin Ap-No Tc-DI-6 & 14.9 & 90.0 & 10.4 & 10.4 & --- & --- \\
\hline Tin Ap-No Tc-DI-7 & 17.9 & 88.0 & 10.4 & 10.4 & --- & --- \\
\hline Tin Ap-No Tc-7.8M-1 & 1.0 & 100.0 & 1930000 & 1860000 & 0.09 & $\mathrm{NA}$ \\
\hline Tin Ap-No Tc-7.8M-2 & 1.9 & 98.0 & 1840000 & 1820000 & 0.63 & -0.04 \\
\hline Tin Ap-No Tc-7.8M-3 & 3.9 & 96.0 & 1790000 & 1840000 & 0.59 & 0.33 \\
\hline Tin Ap-No Tc-7.8M-4 & 6.9 & 94.0 & 2060000 & 2000000 & 0.42 & 0.36 \\
\hline Tin Ap-No Tc-7.8M-5 & 10.9 & 92.0 & 2050000 & 2000000 & 0.87 & 0.30 \\
\hline Tin Ap-No Tc-7.8M-6 & 14.9 & 90.0 & 2060000 & 1900000 & 0.77 & 0.79 \\
\hline Tin Ap-No Tc-7.8M-7 & 17.9 & 88.0 & 1960000 & 2020000 & 0.68 & 0.34 \\
\hline BLK-No Tc-DI-1 & 1.0 & 100.0 & 9.58 & 9.58 & --- & --- \\
\hline BLK-No Tc-DI-2 & 1.9 & 98.0 & 9.58 & 9.58 & --- & --- \\
\hline BLK-No Tc-DI-3 & 3.9 & 96.0 & 9.58 & 9.58 & --- & --- \\
\hline BLK-No Tc-DI-4 & 6.9 & 94.0 & 10.4 & 10.4 & --- & --- \\
\hline BLK-No Tc-DI-5 & 10.9 & 92.0 & 10.4 & 10.4 & --- & --- \\
\hline BLK-No Tc-DI-6 & 14.9 & 90.0 & 10.4 & 10.4 & --- & --- \\
\hline BLK-No Tc-DI-7 & 17.9 & 88.0 & 10.4 & 10.4 & --- & --- \\
\hline BLK-No Tc-7.8M-1 & 1.0 & 100.0 & 1920000 & 1840000 & --- & --- \\
\hline BLK-No Tc-7.8M-2 & 1.9 & 98.0 & 1900000 & 1900000 & --- & --- \\
\hline BLK-No Tc-7.8M-3 & 3.9 & 96.0 & 1930000 & 1830000 & --- & --- \\
\hline BLK-No Tc-7.8M-4 & 6.9 & 94.0 & 2040000 & 2120000 & --- & --- \\
\hline BLK-No Tc-7.8M-5 & 10.9 & 92.0 & 2240000 & 2100000 & --- & --- \\
\hline BLK-No Tc-7.8M-6 & 14.9 & 90.0 & 2130000 & 2050000 & --- & --- \\
\hline BLK-No Tc-7.8M-7 & 17.9 & 88.0 & 2100000 & 2070000 & --- & --- \\
\hline
\end{tabular}

Note:

Values in italics are the estimated limit of quantification. 
Table A.5. Samples for Batch Sorption Experiments in $\mathrm{NaNO}_{3} / \mathrm{NaOH}$ Solutions

\begin{tabular}{|c|c|c|c|c|c|c|}
\hline Sample ID & $\begin{array}{c}\text { Sample } \\
\text { Time } \\
\text { (days) }\end{array}$ & $\begin{array}{c}\text { Solution } \\
\text { Volume } \\
(\mathrm{mL})\end{array}$ & $\begin{array}{c}{[\mathrm{Cr}], A} \\
(\mu \mathrm{g} / \mathrm{L})\end{array}$ & $\begin{array}{c}{[\mathrm{Cr}], \mathrm{B}} \\
(\mu \mathrm{g} / \mathrm{L})\end{array}$ & $\begin{array}{c}\text { Log(avg } \\
\text { Kd), } \\
{[\mathrm{mL} / \mathrm{g}]}\end{array}$ & $\begin{array}{c}\text { Log } \\
\text { stdev(avg } \\
\text { Kd) } \\
\end{array}$ \\
\hline BFS 1-NO ${ }_{3}-$ SolnA-1 & 0.2 & 100.0 & 19100 & 20300 & 1.33 & 0.72 \\
\hline BFS 1-NO $3-$ SolnA-2 & 1.1 & 98.0 & 11200 & 11800 & 2.00 & 0.87 \\
\hline BFS $1-\mathrm{NO}_{3}-$ SolnA-3 & 3.0 & 96.0 & 3360 & 3070 & 2.79 & 1.66 \\
\hline BFS $1-\mathrm{NO}_{3}-$ SolnA-4 & 6.0 & 94.0 & 449 & 208 & 3.95 & 3.67 \\
\hline BFS $1-\mathrm{NO}_{3}-$ SolnA-5 & 10.1 & 92.0 & 208 & 208 & 4.07 & 0 \\
\hline BFS 1-NO 3 -SolnA-6 & 14.1 & 90.0 & 208 & 208 & 4.08 & 0 \\
\hline BFS 1-NO ${ }_{3}-$ SolnA-7 & 17.1 & 88.0 & 208 & 208 & 4.05 & 0 \\
\hline BFS 2-NO 3 -SolnA-1 & 0.2 & 100.0 & 21600 & 21100 & 1.08 & 0.27 \\
\hline BFS 2-NO - -SolnA-2 & 1.1 & 98.0 & 12700 & 13000 & 1.90 & 0.47 \\
\hline BFS 2-NO - -SolnA-3 & 3.0 & 96.0 & 1720 & 1340 & 3.15 & 2.43 \\
\hline BFS 2-NO ${ }_{3}-$ SolnA-4 & 6.0 & 94.0 & 208 & 208 & 4.09 & 0 \\
\hline BFS 2-NO 3 -SolnA-5 & 10.1 & 92.0 & 208 & 208 & 4.07 & 0 \\
\hline BFS 2-NO ${ }_{3}-$ SolnA-6 & 14.1 & 90.0 & 208 & 208 & 4.08 & 0 \\
\hline BFS 2-NO - -SolnA-7 & 17.1 & 88.0 & 208 & 208 & 4.05 & 0 \\
\hline Tin $\mathrm{Ap}-\mathrm{NO}_{3}-\mathrm{Soln} \mathrm{A}-1$ & 0.2 & 100.0 & 192 & 192 & 4.09 & 0 \\
\hline Tin $\mathrm{Ap}-\mathrm{NO}_{3}-$ Soln $\mathrm{A}-2$ & 1.1 & 98.0 & 235 & 263 & 3.97 & 2.74 \\
\hline Tin Ap-NO - -SolnA-3 & 3.0 & 96.0 & 278 & 310 & 3.90 & 2.45 \\
\hline Tin $\mathrm{Ap}-\mathrm{NO}_{3}-\mathrm{Soln} \mathrm{A}-4$ & 6.0 & 94.0 & 1000 & 440 & 3.64 & 3.43 \\
\hline Tin $\mathrm{Ap}-\mathrm{NO}_{3}-$ Soln $\mathrm{A}-5$ & 10.1 & 92.0 & 524 & 435 & 3.74 & 3.08 \\
\hline Tin $\mathrm{Ap}-\mathrm{NO}_{3}-\mathrm{Soln} \mathrm{A}-6$ & 14.1 & 90.0 & 458 & 478 & 3.76 & 2.65 \\
\hline Tin Ap- $\mathrm{NO}_{3}-\mathrm{Soln} \mathrm{A}-7$ & 17.1 & 88.0 & 462 & 617 & 3.68 & 2.56 \\
\hline BLK-NO ${ }_{3}-$ SolnA-1 & 0.2 & 100.0 & 24000 & 23800 & --- & -- \\
\hline BLK-NO ${ }_{3}$-SolnA-2 & 1.1 & 98.0 & 23400 & 23300 & --- & -- \\
\hline BLK-NO ${ }_{3}-$ SolnA-3 & 3.0 & 96.0 & 24300 & 23500 & --- & -- \\
\hline BLK-NO ${ }_{3}-$ SolnA-4 & 6.0 & 94.0 & 26200 & 28500 & --- & --- \\
\hline BLK-NO ${ }_{3}-$ SolnA-5 & 10.1 & 92.0 & 26500 & 26900 & --- & --- \\
\hline BLK-NO ${ }_{3}-$ SolnA-6 & 14.1 & 90.0 & 28500 & 27600 & --- & -- \\
\hline BLK-NO $-\mathrm{N}_{3}$-SolnA-7 & 17.1 & 88.0 & 27100 & 26400 & --- & --- \\
\hline
\end{tabular}

Note:

Values in italics are the estimated limit of quantification. 
Table A.5. (cont.)

\begin{tabular}{|c|c|c|c|c|c|c|}
\hline Sample ID & $\begin{array}{c}\text { Sample } \\
\text { Time } \\
\text { (days) }\end{array}$ & $\begin{array}{c}\text { Solution } \\
\text { Volume } \\
(\mathrm{mL})\end{array}$ & $\begin{array}{c}{[T c], A} \\
(\mu \mathrm{g} / \mathrm{L})\end{array}$ & $\begin{array}{c}{[T c], B} \\
(\mu g / L)\end{array}$ & $\begin{array}{c}\text { Log(avg } \\
\text { Kd), } \\
{[\mathrm{mL} / \mathrm{g}]}\end{array}$ & $\begin{array}{c}\text { Log } \\
\text { stdev(avg } \\
\text { Kd) } \\
\end{array}$ \\
\hline BFS 1-NO ${ }_{3}$-SolnB-4 & 6.1 & 94.0 & 14900 & 16100 & 2.36 & 1.24 \\
\hline BFS $1-\mathrm{NO}_{3}-$ SolnB-5 & 10.0 & 92.0 & 5940 & 8060 & 2.78 & 2.18 \\
\hline BFS 1-NO ${ }_{3}$-SolnB-6 & 14.1 & 90.0 & 982 & 1730 & 3.58 & 3.18 \\
\hline BFS $1-\mathrm{NO}_{3}$-SolnB-7 & 17.1 & 88.0 & 674 & 610 & 3.86 & 2.71 \\
\hline BFS 2-NO ${ }_{3}-$ SolnB-4 & 6.1 & 94.0 & 4070 & 923 & 3.51 & 3.47 \\
\hline BFS 2-NO ${ }_{3}-$ SolnB-5 & 10.0 & 92.0 & 1080 & 1190 & 3.62 & 2.46 \\
\hline BFS 2-NO ${ }_{3}-$ SolnB-6 & 14.1 & 90.0 & 879 & 704 & 3.78 & 2.99 \\
\hline BFS 2-NO ${ }_{3}-$ SolnB-7 & 17.1 & 88.0 & 285 & 395 & 4.15 & 3.51 \\
\hline Tin $\mathrm{Ap}-\mathrm{NO}_{3}-\mathrm{SolnB}-4$ & 6.1 & 94.0 & 14300 & 10000 & 2.54 & 2.12 \\
\hline Tin $\mathrm{Ap}-\mathrm{NO}_{3}-\mathrm{SolnB}-5$ & 10.0 & 92.0 & 15400 & 9910 & 2.52 & 2.20 \\
\hline Tin Ap- $\mathrm{NO}_{3}-\mathrm{SolnB}-6$ & 14.1 & 90.0 & 13900 & 9100 & 2.59 & 2.26 \\
\hline Tin Ap- $\mathrm{NO}_{3}-\mathrm{SolnB}-7$ & 17.1 & 88.0 & 12800 & 8970 & 2.60 & 2.24 \\
\hline BLK-NO ${ }_{3}$-SolnB-4 & 6.1 & 94.0 & 52800 & 52800 & --- & $-\cdots$ \\
\hline BLK-NO ${ }_{3}-$ SolnB-5 & 10.0 & 92.0 & 52100 & 52100 & --- & -- \\
\hline BLK-NO ${ }_{3}-$ SolnB-6 & 14.1 & 90.0 & 53700 & 53700 & --- & -- \\
\hline BLK-NO ${ }_{3}-$ SolnB-7 & 17.1 & 88.0 & 53000 & 53000 & --- & -- \\
\hline
\end{tabular}


Table A.6. Samples for Batch Sorption Experiments in $\mathrm{NaNO}_{3} / \mathrm{NaOH}$ Solutions

\begin{tabular}{|c|c|c|c|c|c|c|}
\hline Sample ID & $\begin{array}{c}\text { Sample } \\
\text { Time } \\
\text { (days) }\end{array}$ & $\begin{array}{c}\text { Solution } \\
\text { Volume } \\
\text { (mL) }\end{array}$ & $\begin{array}{c}{[T c], A} \\
(\mu g / L)\end{array}$ & $\begin{array}{c}{[\mathrm{Tc}], \mathrm{B}} \\
(\mu \mathrm{g} / \mathrm{L})\end{array}$ & $\begin{array}{c}\text { Log(avg } \\
\text { Kd), } \\
{[\mathrm{mL} / \mathrm{g}]}\end{array}$ & $\begin{array}{c}\text { Log } \\
\text { stdev(avg } \\
\text { Kd) }\end{array}$ \\
\hline BFS 1-NO ${ }_{3}$-SolnC-4 & 6.1 & 94.0 & 51600 & 51300 & 0.47 & -0.40 \\
\hline BFS $1-\mathrm{NO}_{3}$-SolnC-5 & 10.0 & 92.0 & 54500 & 52000 & 0 & 0 \\
\hline BFS 1-NO ${ }_{3}$-SolnC-6 & 14.1 & 90.0 & 53200 & 50800 & 0.44 & 0 \\
\hline BFS 1-NO $-\mathrm{NO}_{3}$-SolnC-7 & 17.1 & 88.0 & 52600 & 50100 & 0 & 0 \\
\hline BFS 2-NO ${ }_{3}$-SolnC-4 & 6.1 & 94.0 & 53700 & 54100 & 0 & 0 \\
\hline BFS 2-NO $-\mathrm{NO}_{3}$-SolnC-5 & 10.0 & 92.0 & 52300 & 53300 & 0 & 0 \\
\hline BFS 2-NO ${ }_{3}$-SolnC-6 & 14.1 & 90.0 & 51200 & 50100 & 0.48 & 0.15 \\
\hline BFS 2- $\mathrm{NO}_{3}$-SolnC-7 & 17.1 & 88.0 & 52500 & 54700 & 0 & 0 \\
\hline Tin $\mathrm{Ap}-\mathrm{NO}_{3}-\mathrm{SolnC}-4$ & 6.1 & 94.0 & 55300 & 50900 & 0.64 & 0 \\
\hline Tin Ap- $\mathrm{NO}_{3}-\mathrm{SolnC}-5$ & 10.0 & 92.0 & 54500 & 51100 & 0.26 & 0 \\
\hline Tin $\mathrm{Ap}-\mathrm{NO}_{3}-$ SolnC-6 & 14.1 & 90.0 & 53300 & 52000 & -0.15 & 0 \\
\hline Tin $\mathrm{Ap}-\mathrm{NO}_{3}-$ SolnC-7 & 17.1 & 88.0 & 52000 & 50400 & 0 & 0 \\
\hline BLK-NO ${ }_{3}-$ SolnC-4 & 6.1 & 94.0 & 56000 & 50100 & --- & -- \\
\hline BLK-NO $-\mathrm{NO}_{3}-$ SolnC-5 & 10.0 & 92.0 & 54100 & 49900 & --- & --- \\
\hline BLK-NO ${ }_{3}-$ SolnC-6 & 14.1 & 90.0 & 52800 & 51900 & --- & --- \\
\hline BLK-NO ${ }_{3}-$ SolnC-7 & 17.1 & 88.0 & 50500 & 49500 & --- & -- \\
\hline
\end{tabular}


Table A.7. pH of Selected Experiments

\begin{tabular}{|l|c|c|c|c|}
\hline Getter & Experiment & Solution & Replicate & pH \\
\hline BFS 1 & No Tc & DI & A & 11.95 \\
BFS 1 & No Tc & DI & B & 11.78 \\
BFS 1 & No Tc & 7.8M & A & 13.85 \\
BFS 1 & No Tc & 7.8M & B & 13.88 \\
\hline BFS 2 & No Tc & DI & A & 11.97 \\
BFS 2 & No Tc & DI & B & 11.94 \\
BFS 2 & No Tc & 7.8M & A & 13.89 \\
BFS 2 & No Tc & 7.8M & B & 13.90 \\
\hline Tin-Ap & No Tc & DI & A & 7.26 \\
Tin-Ap & No Tc & DI & B & 7.15 \\
Tin-Ap & No Tc & 7.8M & A & 13.71 \\
Tin-Ap & No Tc & 7.8M & B & 13.75 \\
\hline Blank & No Tc & DI & A & 9.70 \\
Blank & No Tc & DI & B & 8.04 \\
Blank & No Tc & 7.8M & A & 13.68 \\
Blank & No Tc & 7.8M & B & 13.72 \\
\hline BFS 1 & nitrate & A & A & 13.71 \\
BFS 1 & nitrate & A & B & 13.71 \\
BFS 2 & nitrate & A & A & 13.71 \\
BFS 2 & nitrate & A & B & 13.70 \\
\hline Tin-Ap & nitrate & A & A & 13.72 \\
Tin-Ap & nitrate & A & B & 13.74 \\
Blank & nitrate & A & A & 13.74 \\
Blank & nitrate & A & B & --- \\
\hline BFS 1 & nitrate & C & A & 13.21 \\
BFS 1 & nitrate & C & B & 13.27 \\
BFS 2 & nitrate & C & A & 13.29 \\
BFS 2 & nitrate & C & B & 13.31 \\
\hline Tin-Ap & nitrate & C & A & 13.34 \\
Tin-Ap & nitrate & C & B & 13.36 \\
Blank & nitrate & C & A & 13.34 \\
Blank & nitrate & C & B & 13.37 \\
\hline
\end{tabular}


PNNL-23667 Rev. 1 EMSP-RPT-026 Rev. 1

\section{Distribution*}

U.S. Department of Energy

Office of Environmental Management

DJ Koutsandreas

NP Machara

JA Poppiti

SP Schneider

U.S. Department of Energy

Office of River Protection

JA Diediker

RA Gilbert

CC Harrington

AA Kruger

SH Pfaff

Washington River Protection Solutions

PA Cavanah

WG Ramsey

KH Subramanian

DJ Swanberg

Savannah River National Laboratory

AD Cozzi

KM Fox

DI Kaplan

SL Marra

DJ McCabe
Pacific Northwest National Laboratory

CF Brown

SA Bryan

TG Levitskaia

GG Lumetta

JJ Neeway

RA Peterson

NP Qafoku

BM Rapko

S Schlahta

RJ Serne

W Um

JD Vienna

DM Wellman

JH Westsik, Jr.

\footnotetext{
*All distribution will be made electronically.
} 


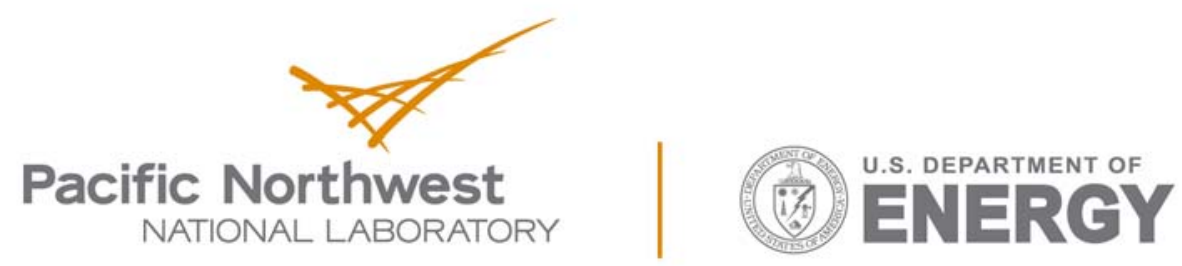

Proudly Operated by Battelle Since 1965

902 Battelle Boulevard

P.O. Box 999

Richland, WA 99352

1-888-375-PNNL (7665)

www.pnnl.gov 